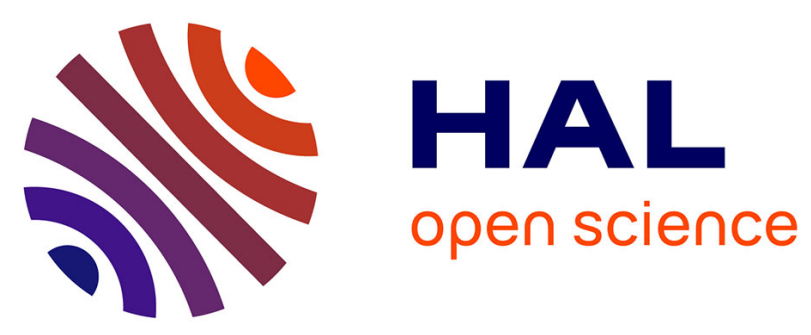

\title{
Glycerol Acetals and Ketals as Bio-based Solvents: Positioning in Hansen and COSMO-RS spaces, Volatility and Stability towards Hydrolysis and Autoxidation
}

\author{
Laurianne Moity, Adrien Benazzouz, Valérie Molinier, Véronique
}

Nardello-Rataj, Mohammed Kamal Elmkaddem, Pascale de Caro, Sophie

Thiebaud-Roux, Vincent Gerbaud, Philippe Marion, Jean-Marie Aubry

\section{To cite this version:}

Laurianne Moity, Adrien Benazzouz, Valérie Molinier, Véronique Nardello-Rataj, Mohammed Kamal Elmkaddem, et al.. Glycerol Acetals and Ketals as Bio-based Solvents: Positioning in Hansen and COSMO-RS spaces, Volatility and Stability towards Hydrolysis and Autoxidation. Green Chemistry, 2015, vol. 17 ( $\mathrm{n}^{\circ} 3$ ), pp. 1779-1792. 10.1039/c4gc02377c . hal-01198815

\section{HAL Id: hal-01198815 https://hal.science/hal-01198815}

Submitted on 14 Sep 2015

HAL is a multi-disciplinary open access archive for the deposit and dissemination of scientific research documents, whether they are published or not. The documents may come from teaching and research institutions in France or abroad, or from public or private research centers.
L'archive ouverte pluridisciplinaire HAL, est destinée au dépôt et à la diffusion de documents scientifiques de niveau recherche, publiés ou non, émanant des établissements d'enseignement et de recherche français ou étrangers, des laboratoires publics ou privés. 


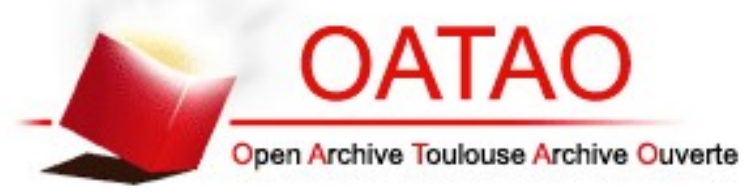

\section{Open Archive TOULOUSE Archive Ouverte (OATAO)}

OATAO is an open access repository that collects the work of Toulouse researchers and makes it freely available over the web where possible.

This is an author-deposited version published in : http://oatao.univ-toulouse.fr/ Eprints ID : 12226

To link to this article : DOI: $10.1039 / \mathrm{c} 4 \mathrm{gc} 02377 \mathrm{c}$

URL : http://dx.doi.org/10.1039/c4gc02377c

To cite this version : Moity, Laurianne and Benazzouz, Adrien and Molinier, Valérie and Nardello-Rataj, Véronique and Elmkaddem, Mohammed Kamal and De Caro, Pascale and Thiebaud-Roux, Sophie and Gerbaud, Vincent and Marion, Philippe and Aubry, Jean-Marie Glycerol Acetals and Ketals as Bio-based Solvents: Positioning in Hansen and COSMO-RS spaces, Volatility and Stability towards Hydrolysis and Autoxidation. (2015) Green Chemistry, vol. 17 ( $\left.\mathrm{n}^{\circ} 3\right)$. pp. 1779-1792. ISSN 1463-9262

Any correspondance concerning this service should be sent to the repository administrator: staff-oatao@listes-diff.inp-toulouse.fr 


\title{
Glycerol Acetals and Ketals as Bio-based Solvents: Positioning in Hansen and COSMO-RS spaces, Volatility and Stability towards Hydrolysis and Autoxidation
}

\begin{abstract}
Laurianne Moity, ${ }^{a}$ Adrien Benazzouz, ${ }^{a}$ Valérie Molinier, ${ }^{a}$ Véronique Nardello-Rataj, ${ }^{a}$ Mohammed Kamal Elmkaddem, ${ }^{b, c}$ Pascale de Caro, ${ }^{b, c}$ Sophie Thiébaud-Roux, ${ }^{b, c}$ Vincent Gerbaud, ${ }^{d}$ Philippe Marion, ${ }^{e}$ Jean-Marie Aubry ${ }^{a_{*}}$
\end{abstract}

a Université Lille 1, ENSCL, E.A. 4478 Chimie Moléculaire et Formulation, Cité Scientifique, 59652 Villeneuve d'Ascq Cedex, France, Jean-Marie.Aubry@univ-lille1.fr

${ }^{b}$ Université de Toulouse, INP, LCA (Laboratoire de Chimie Agro-Industrielle), ENSIACET, 4 Allée Emile Monso, 31030 Toulouse, France

${ }^{\mathrm{c}}$ INRA, UMR 1010 CAI, 31030 Toulouse, France

' Université de Toulouse, INP, CNRS, LGC (Laboratoire de Génie Chimique), ENSIACET, 4 Allée Emile Monso, 31432 Toulouse, France

e Solvay Recherches \& Innovation, Centre de Lyon, 85 rue des Frères Perret, 69192 Saint-Fons Cedex, France

\section{ABSTRACT}

Four recently launched cyclic glycerol acetals or ketals are evaluated as bio-based solvents. Three of them are industrially available and result from the condensation of glycerol with formaldehyde, acetone and isobutyl methyl ketone. The fourth is under development and is prepared by the reaction of glycerol with benzaldehyde under heterogeneous acidic catalysis. Their solvent properties are evaluated through Hansen and COSMO-RS (COnductor-like Screening MOdel for Real Solvents) approaches, in comparison to traditional petrochemical solvents. Dioxolane- and dioxane-type isomers have close solubility parameters; however the nature of the starting aldehyde/ketone significantly impacts the solvency properties. Stability to hydrolysis depends heavily on both the aldehyde/ketone part and on the size of the ring. In acidic medium, acetals are found to be more stable than ketals and glycerol-based ketals are more stable than ethylene glycol-based ketals. In the case of benzaldehyde glycerol acetal, it is shown that the 6-member ring isomer (dioxane-type) is approximately 8 times more stable than the 5-member ring counterpart (dioxolane-type) at low $\mathrm{pH}$. Stability towards autoxidation by $\mathrm{O}_{2}$ is high for formaldehyde and acetone-derived acetals and drops for the other two compounds. Glycerol acetals and ketals are promising potential alternatives to some harmful solvents such as glycol ethers and aniline.

\section{KEYWORDS}

Acetals, ketals, glycerol, bio-based solvents, hydrolysis, autoxidation, Hansen solubility parameters, cosMo-RS. 


\section{INTRODUCTION}

The chemical industry is increasingly turning to so-called "bio-based" solutions, as a remedy to dwindling fossil resources and greenhouse gases emissions, and as part of its commitment to "sustainable development". The so-called "bio-based solvents" are a class of commodity chemicals that already represent a mature market ${ }^{1-3}$. They are obtained from the biomass feedstock ${ }^{4-8}$ and experience an increased demand due to the regulatory constraints that restrict the use of a large number of traditional organic solvents, such as halogenated, aromatic or ethylene glycol ethers derivatives.

As a by-product of biodiesel manufacture, glycerol is one of the top-ranking bio-building blocks ${ }^{9-12}$ and has received considerable attention. An appreciable number of chemical intermediates and commodity chemicals can now be obtained from glycerol through optimised catalytic routes. ${ }^{13-19}$ Apart from glycerol itself, several classes of bio-based solvents are currently obtained from glycerol ${ }^{20-24}$ (Figure 1).

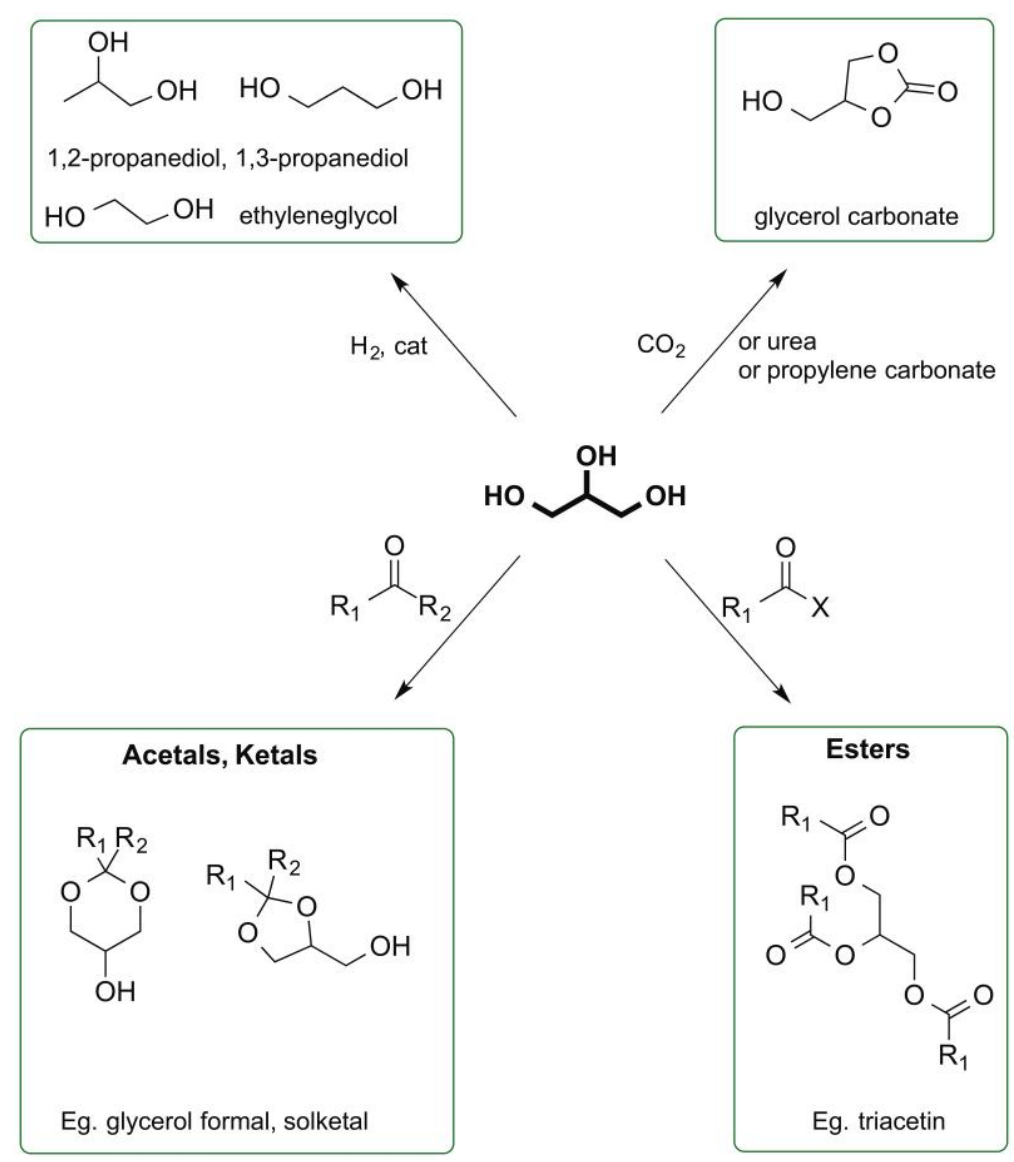

Fig.1 Families of bio-based solvents derived from glycerol.

Hydrogenolysis of glycerol gives rise to propanediols and ethylene glycol that are common solvents and for which an efficient bio-derived route is competitive to the traditional petrochemical route. Glycerol triacetate (triacetin) is obtained by glycerol esterification and is used as solvent and additive in various fields, including food and pharmaceutical formulations. Glycerol carbonate is prepared by carbonation or transcarbonation of glycerol and is on the market for cosmetic, personal care and 
medicinal applications due to its low toxicity and low flammability. Finally, the cyclic acetals (respectively ketals) are synthesised by the condensation of two alcohol functions of glycerol with an aldehyde (respectively a ketone). The final compound can be fully bio-based if the aldehyde or ketone used is bio-sourced (for example acetaldehyde, acetone and benzaldehyde).

The acetals/ketals of glycerol have only recently been classified as low toxicity bio-based solvents, even though they have been known for a long time as chemical intermediates. In particular, 1,2isopropylidene glycerol (solketal) is commonly used in organic synthesis to introduce the protected form of the glycerol moiety in a molecular scaffold. Its solvent properties have been recently highlighted, since it is now manufactured on an industrial scale at competitive cost. ${ }^{25}$ Several patents describe the use of acetals/ketals of glycerol as solvents, coalescing agents in paints or lacquers or as coupling agents. ${ }^{26-31}$ In some formulations, they advantageously replace prohibited (e.g. 2methoxyethanol) or controversial (e.g. 2-butoxyethanol) short ethylene glycol ethers. Glycerol acetals and ketals are also produced as bio-additive fuels ${ }^{32-35}$ to decrease emissions of carbon monoxide, hydrocarbons and unregulated aldehydes and as cold flow improvers. ${ }^{32,36}$

These glycerol derivatives are usually prepared by condensation of glycerol with carbonyl compounds, catalysed by homogeneous catalysts such as gold or iridium complexes. ${ }^{37-39}$ Heterogeneous catalysts such as zeolites, ${ }^{40-42}$ ion exchange resins, ${ }^{43,44}$ montmorillonites ${ }^{45,46}$ and sulfonic mesostructured silicates ${ }^{47}$ are also reported to be active for acetalisation or ketalisation. Some of these catalysts (Amberlyst-36, ${ }^{43}$ metal oxides ${ }^{33}$ or silica supported catalyst ${ }^{48}$ ) proved to be efficient for the conversion of benzaldehyde with glycerol. The selectivities obtained towards 5- and 6-member ring derivatives (1,3-dioxolane and 1,3-dioxane types) depend on the experimental conditions. Recently, GonzalezArellano et al. described the preparation of glycerol acetals using aluminium substituted mesoporous material AI-SBA-15 in high yields and tuneable selectivities towards 5- and 6-member ring isomers depending on the starting aldehyde/ketone. ${ }^{49}$

In this work, we intend to compare four cyclic glycerol acetals and ketals 1-4, recently launched at an industrial scale, with petrochemical solvents having acetal or ether functions 5-19. The solvent properties are evaluated through the traditional Hansen's approach and also via the theoretical COSMO-RS model. Particular interest is given to their volatility, oxidability and stability towards hydrolysis in aqueous medium since they are key parameters to be considered in the selection of a suitable solvent. The four cyclic glycerol acetals or ketals selected are glycerol formal $\mathbf{1} \mathbf{a}+\mathbf{1 b}, \mathbf{1}, 2-$ isopropylidene glycerol (solketal) 2, 1,2-methylisobutylidene glycerol 3 and benzaldehyde glycerol acetal (BGA) $\mathbf{4 a + 4 b}$ (see table 1). Acetals 1 and $\mathbf{4}$ are mixtures of 5 - and 6 - member ring derivatives (see experimental section). Acetal 4 was prepared by condensation of glycerol with benzaldehyde using a macroporous ion exchange resin.

\section{RESULTS AND DISCUSSION}

For the sake of clarity, the synthesis of benzaldehyde glycerol acetal $\mathbf{4 a} \mathbf{a} \mathbf{4 b}$ is given in the ESI. The aim of the present paper is indeed not to discuss the synthesis, all the more that a recent paper describes in details the preparation of acetals and ketals investigated in the present work. ${ }^{49}$ We rather 
focus on the potentialities of compounds $\mathbf{1}$ - $\mathbf{4}$ as bio-based solvents and therefore study their relevant physical and chemical properties. The solvent properties per se are evaluated through the traditional Hansen's parameters and the more modern COSMO-RS approach. Special interest was also paid to volatility that often triggers the choice of a solvent. Finally, stabilities towards hydrolysis and autoxidation are examined and compared to the one of other relevant solvents 5-20 (Table 1) since these compounds are prone to cleave in acidic solutions and to suffer free radical chain oxidation with oxygen.

Table 1 Number, name and structure of the glycerol acetals/ketals $1-4$ and of the various solvents studied in this work for comparison with regard to volatility, hydrolysis and oxidability.

\begin{tabular}{|c|c|c|c|c|}
\hline $\mathrm{N}^{\circ}$ & Name & $\mathrm{N}^{\circ}$ & Name & Structure \\
\hline $1 \mathrm{a}$ & $\begin{array}{l}\text { Glycerol formal } \\
\text { (dioxolane) }\end{array}$ & 10 & Methylal & \\
\hline $1 b$ & $\begin{array}{l}\text { Glycerol formal } \\
\text { (dioxane) }\end{array}$ & 11 & Ethylal & \\
\hline 2 & Solketal & 12 & $n$-Butyl acetate & \\
\hline 3 & $\begin{array}{l}\text { 1,2-Methylisobutylidene } \\
\text { glycerol }\end{array}$ & 13 & $\begin{array}{l}\text { Ethylene glycol } \\
n \text {-butyl ether }\left(\mathrm{C}_{4} \mathrm{E}_{1}\right)\end{array}$ & \\
\hline $4 \mathbf{a}$ & $\begin{array}{l}\text { Benzaldehyde glycerol } \\
\text { acetal (dioxolane) }\end{array}$ & 14 & $\begin{array}{l}\text { Propylene glycol } \\
\text { n-butyl ether }\left(\mathrm{C}_{4} \mathrm{P}_{1}\right)\end{array}$ & \\
\hline $4 b$ & $\begin{array}{l}\text { Benzaldehyde glycerol } \\
\text { acetal (dioxane) }\end{array}$ & 15 & $\begin{array}{l}\text { Diethylene glycol } \\
\text { ethyl ether }\left(\mathrm{C}_{2} \mathrm{E}_{2}\right)\end{array}$ & \\
\hline 5 & 1,3-Dioxolane & 16 & $\begin{array}{l}\text { Diethylene glycol } \\
\text { butyl ether }\left(\mathrm{C}_{4} \mathrm{E}_{2}\right)\end{array}$ & \\
\hline 6 & 2-Methyl-1,3-dioxolane & 17 & $\begin{array}{l}\text { Diethylene glycol } \\
\text { hexyl ether }\left(\mathrm{C}_{6} \mathrm{E}_{2}\right)\end{array}$ & \\
\hline 7 & $\begin{array}{l}\text { 2,2-Dimethyl-1,3- } \\
\text { dioxolane }\end{array}$ & 18 & $\begin{array}{l}\text { Tetrahydrofurfuryl } \\
\text { alcohol }\end{array}$ & \\
\hline 8 & $\begin{array}{l}\text { 2,2,4-Trimethyl-1,3- } \\
\text { dioxolane }\end{array}$ & 19 & Dimethyl isosorbide & \\
\hline 9 & 1,4-Dioxane & 20 & Limonene & \\
\hline
\end{tabular}




\section{Solvent properties}

Glycerol acetals/ketals $\mathbf{1}$ to $\mathbf{4}$ are first considered using the traditional Hansen's approach. In this semiempirical theory, the solubilising properties of solvents are characterized by three parameters corresponding to dispersion $\delta_{d}$, polar $\delta_{p}$ and hydrogen bonding $\delta_{h}$ interactions, which build a threedimensional space known as the "Hansen space". ${ }^{50,53,54}$ Solvents that are located close to each other in this space are expected to exhibit similar solubilising behaviours. This simple approach has a broad acceptance in the industrial community. It allows identifying in a rather reliable way the good solvents for a given solute thanks to the chemical rule of similarity, ${ }^{54}$ provided that the solubility parameters of the solute and solvents are known. The Hansen solubility parameters of the four glycerol acetals/ketals 1-4 and other relevant petro-based acetals/ketals/ethers solvents 5-11 have been computed using the recommended Y-MB method (ESI). Figure 2 shows the positioning of glycerol acetals/ketals 1-4 in the $\delta_{\mathrm{p}} / \delta_{\mathrm{h}}$ projection of the Hansen's space, among classical solvents and other acetalic solvents. The relative sizes of the dots account for the $\delta_{d}$ values.

As expected, glycerol acetals/ketals 1-4 (green dots) have significantly higher hydrogen bonding parameters than other acetalic solvents 5-11 (red dots) due to the pending hydroxyl group. The aldehyde/ketone from which they have been prepared also impacts on their position in the Hansen space. Since dioxolane and dioxane isomers $\mathbf{1 a} / \mathbf{1 b}$ and $\mathbf{4 a / 4 b}$ have almost the same Hansen parameters, each couple of isomer is represented by a single dot.

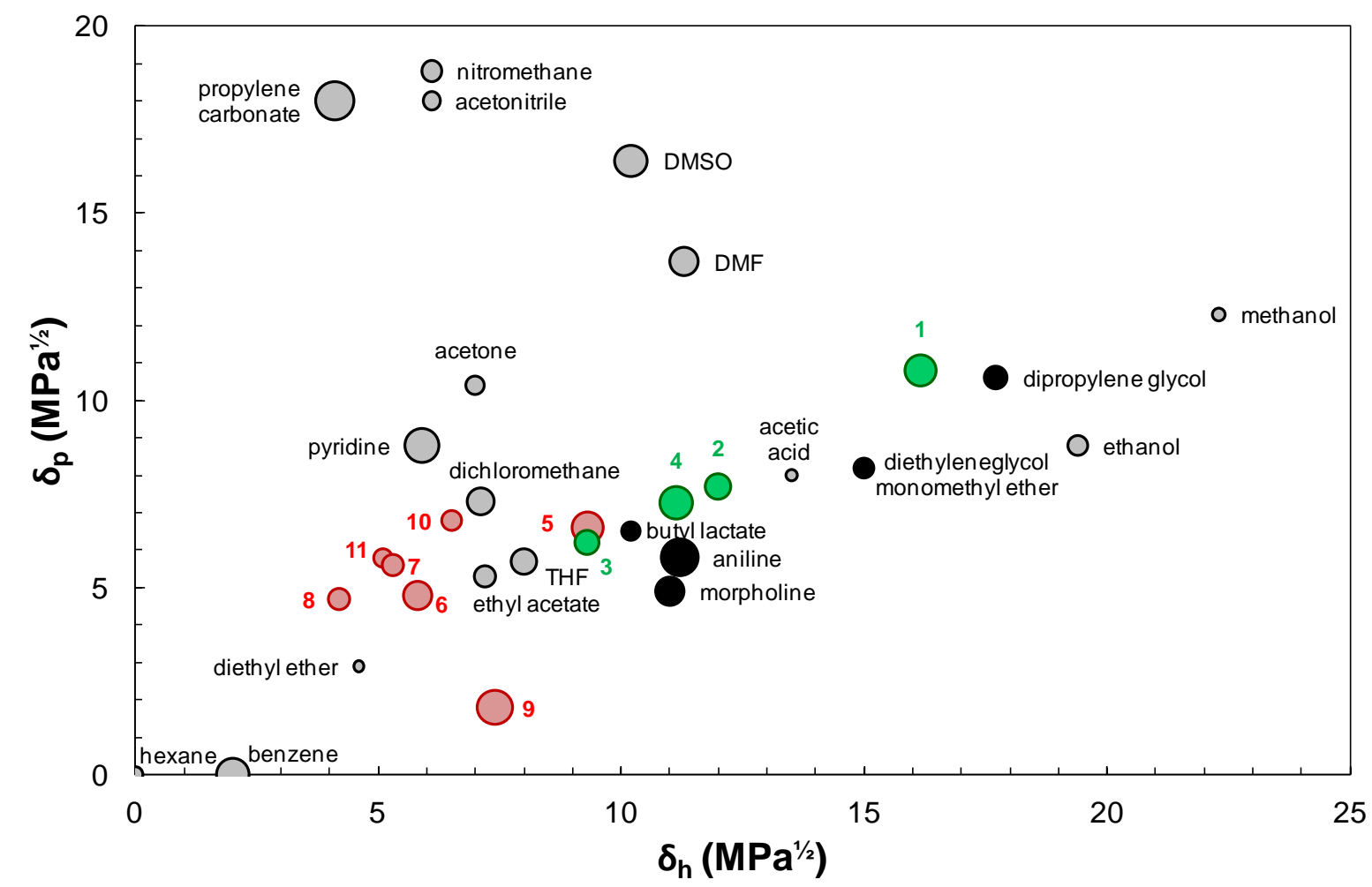

Fig. 2 Location of the four glycerol acetals/ketals 1-4 within the $\delta_{\mathrm{p}} / \delta_{\mathrm{h}}$ projection of the Hansen space. The sizes of the dots express the $\delta_{d}$ value of the solvent. The four solvents 1-4 are represented in green while classical solvents are in grey and close neighbours are in black. Other acetalic solvents 5-11 are also positioned for comparison (red dots). When not listed in Hansen's list, ${ }^{50}$ solubility parameters were calculated using the Yamamoto Molecular Break method (Y-MB) 
In parallel, acetals/ketals 1-4 have been modelled using the COSMO-RS approach. We have recently used this purely predictive method based on quantum mechanics and statistical thermodynamics to rebuild an a priori classification of organic solvents. ${ }^{51}$ From the knowledge of the chemical structure and without resorting to any experimental data, 10 consistent solvents families were identified. This classification was then used to establish a panorama of currently available "green solvents". ${ }^{7}$ This methodology gives access to a so-called "COSMO-RS 4-dimensionnal space" in which each solvent is identified by four coordinates F1, F2, F3 and F4 resulting from a PCA analysis. This space can be viewed as a purely predictive and more consistent alternative to the 3-dimensionnal semi-empirical "Hansen space". The coordinates of acetals/ketals 1-4 in the COSMO-RS space were calculated according to a procedure previously described. ${ }^{7,51}$ (see ESI) The COSMO-RS approach allows positioning solvents $\mathbf{1 - 4}$ in the ten classes previously established: Solketal 2 and 1,2methylisobutylidene glycerol $\mathbf{3}$ both belong to amphiprotic solvents, just as most alcohols, whereas glycerol formal $\mathbf{1}$ is positioned in the polar protic family among short alcohols and polyols, which evidences its higher tendency to establish hydrogen bonds. Benzaldehyde glycerol acetal $\mathbf{4}$ is found at the border of the amphiprotic family and the polar protic family which contains furfuryl alcohol, 2aminoethanol as well as diethylene glycol.

Both approaches can be used to identify the closest classical solvents by calculating the distance $D$ separating them from each glycerol acetal/ketal 1-4 in the 3D-Hansen space or in the 4D-COSMO-RS space (see experimental part). Solvents taken as references are the 88 conventional solvents used by Hansen to determine its solubility parameters. ${ }^{50} \mathrm{~A}$ simple method to visually locate the nearest neighbour of a given solvent in the Hansen space (Figure 2) is to search among the closest points, the one which has a similar diameter (similar $\delta_{d}$ ). The nearest neighbours of 1-4 are reported in Table 2, while the ranking obtained by the other method is indicated in parentheses. For $\mathbf{1}$ and $\mathbf{4}$, only the neighbours of the mixture of isomers $\mathbf{1} \mathbf{a} / \mathbf{1} \mathbf{b}$ (34:66) and $\mathbf{4 a / 4 b}(66: 34)$ are shown since dioxolane and dioxane isomers exhibit almost similar coordinates, with only slight differences in the ranking (see ESI).

Table 2 Closest neighbours of glycerol acetals/ketals 1-4 in the Hansen's space $(H)$ and in the COSMO-RS space (C). Solvents taken as references are the 88 classical solvents used by Hansen to determine its solubility parameters. ${ }^{50}$ The ranking and coordinates of all solvents can be found in ESI.

\begin{tabular}{|c|c|c|c|c|c|c|c|c|}
\hline \multirow{3}{*}{ Classical solvents } & \multicolumn{8}{|c|}{ Ranking of closest classical solvents from acetals/ketals 1-4 } \\
\hline & \multicolumn{2}{|c|}{$1 a+1 b$} & \multicolumn{2}{|c|}{2} & \multicolumn{2}{|c|}{3} & \multicolumn{2}{|c|}{$4 a+4 b$} \\
\hline & $\mathrm{H}$ & $\mathrm{C}$ & $\mathrm{H}$ & C & $\mathrm{H}$ & C & $\mathrm{H}$ & $\mathrm{C}$ \\
\hline Dipropylene glycol & 1 & (17) & - & - & - & - & - & - \\
\hline Aniline & (22) & 1 & - & - & - & - & (3) & 1 \\
\hline Diethylene glycol monomethyl ether & - & - & 1 & $(15)$ & - & - & - & - \\
\hline Butyl lactate & - & - & (6) & 1 & (2) & 1 & - & - \\
\hline Tetrahydrofuran & - & - & - & - & 1 & (66) & - & - \\
\hline Morpholine & - & - & - & - & - & - & 1 & (79) \\
\hline
\end{tabular}

For several solvents, the rankings obtained by Hansen and COSMO-RS methods are consistent. This is the case for butyl lactate which is found close to $\mathbf{2}$ and $\mathbf{3}$ as well as for aniline which is close to $\mathbf{4}$ 
whatever the method. Both methods identify several short chain glycol ethers as close neighbours of solketal 2 , which means that this compound might be a safe alternative to this family of reprotoxic solvents. Actually, 2 is already used to substitute 2-methoxyethanol in aqueous formulations as a coupling agent. ${ }^{28}$ Surprisingly, several aromatic conventional solvents are encountered in the vicinity of 1-4 according to the COSMO-RS method. For instance, aniline is the closest solvent of glycerol formal 1 and benzaldehyde glycerol acetal 4. Presumably, the strong electronic density in the acetalic cycle brought by the doublets of the oxygen atoms compensates the lack of aromatic electrons of 1-3. In contrast, two solvents, namely THF and morpholine are very close to $\mathbf{3}$ and $\mathbf{4}$ respectively in Hansen's space whereas they are far apart in COSMO-RS space.

To shed some light on the origin of these discrepancies, we drew in Figures 3a-d, the $\sigma$-potential curves of glycerol acetals / ketals 1-4 (green curves) and of their closest solvents determined either by Hansen approach (black curves) or COSMO-RS (red curves).
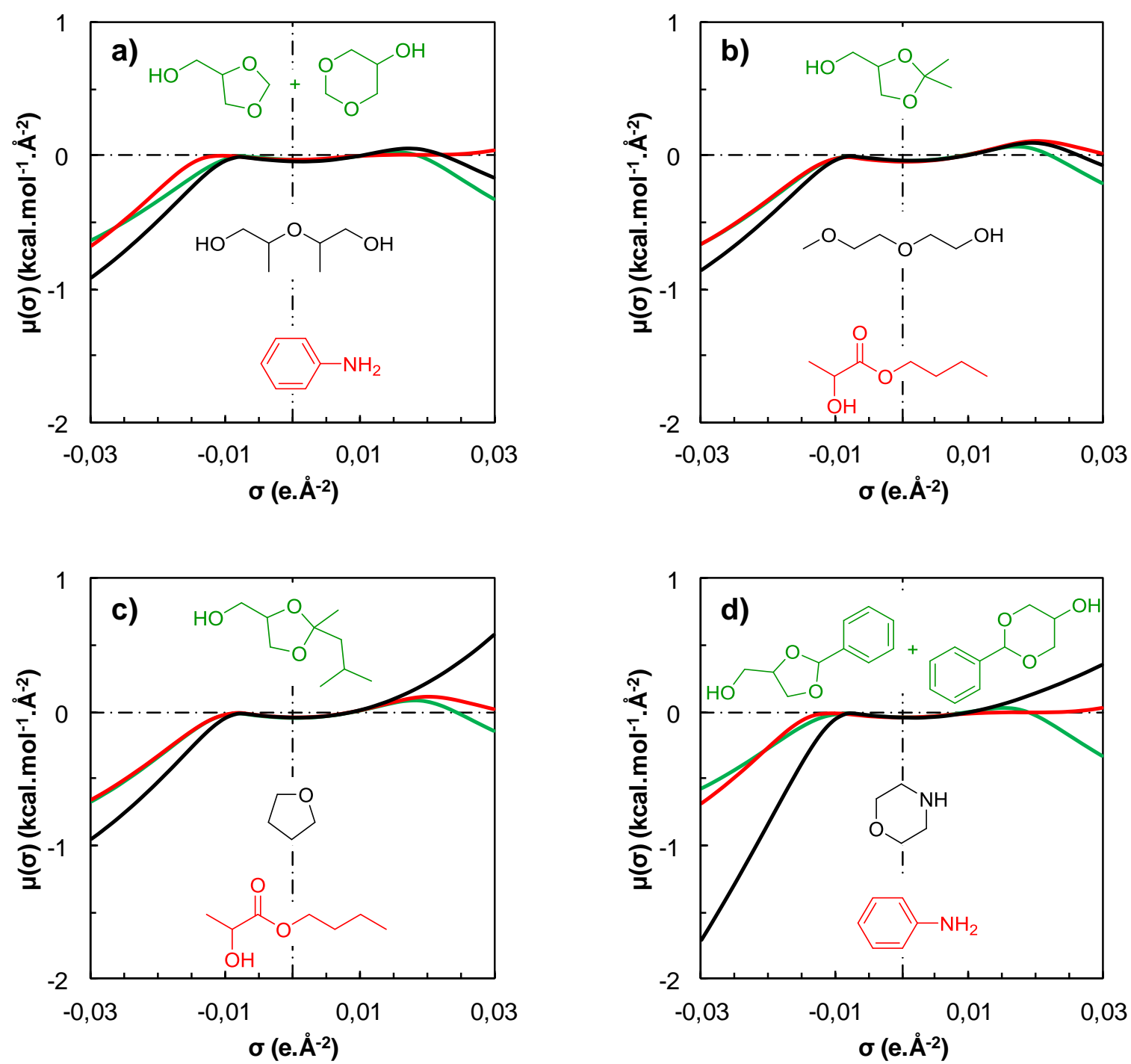

Fig. 3 o-potentials computed with COSMO-RS for the glycerol acetals/ketals 1-4 (green curves) and their closest neighbours according to Hansen (black curves) or COSMO-RS (red curves). a) glycerol formal 1 (green), dipropylene glycol (black) and aniline (red). b) solketal 2 (green), diethylene glycol monomethyl ether (black) and butyl lactate (red). c) 1,2-methylisobutylidene glycerol ketal 3 (green), tetrahydrofuran (black) and butyl lactate (red). d) benzaldehyde glycerol acetal (green), morpholine (black) and aniline (red). 
A $\sigma$-potential curve finely summarizes all the information necessary to apprehend the solubilising properties of the corresponding solvent. ${ }^{51,54}$ Here we only recall the two main informations that can be inferred from a simple observation of the shape of the curves. The left branch reflects the Lewis basicity of the solvent i.e. the presence of electron-rich sites. For solvents that have no basic sites such as alkanes, the left branch is oriented upward. The more the solvent is basic, the more inclined downwardly the branch is. The interpretation of the right branch is similar to the left one except that, in this case, the Lewis acidity is concerned.

Figure 3a shows that the $\sigma$-potential curves of glycerol formal $\mathbf{1}$ and its nearest neighbours found by Hansen and COSMO-RS approaches, are quite similar. They all have a poor acidity and a medium basicity including aniline whose electron pair localized on the nitrogen atom is much less basic than the one of aliphatic amine because it is delocalized on the aromatic ring $\left(\mathrm{pK}_{\mathrm{a}}=4.6\right.$ compared to $\mathrm{pK}_{\mathrm{a}}=$ 10.8 for $\mathrm{NEt}_{3}$ ). It is worth to note that COSMO-RS suitably captures the negligible acidity of the three solvents and the similarity between 1 and aniline, what could hardly be expected by comparing the chemical formulas. In the case of solketal 2 , figures 2 and $3 b$ show that both approaches agree to predict that it should present solubilising properties similar to those of butyl lactate and diethylene glycol monomethyl ether. Ketal $\mathbf{3}$ is predicted to be close to tetrahydrofuran and butyl lactate according to the Hansen approach and COSMO-RS respectively. Looking at the chemical formulas, one can easily admit that $\mathbf{3}$ and butyl lactate should present similar solubilising properties. On the other hand, it is clear that THF and $\mathbf{3}$ must be significantly different due to the lack of alcohol function in the formula of THF. This hydroxyl group allows 3 to establish hydrogen bonds with basic solutes unlike THF. This difference appears clearly on the shape of the right branches of $\sigma$-potential curves in Figure $3 \mathrm{c}$. That of THF is directed upwards in agreement with its lack of acidity, while the other two are curved slightly downward. The closest neighbours of 4 are morpholine and aniline according to the $D_{\text {Hansen }}$ and

$D_{\text {cosmo }}$ criteria respectively. Looking at Figure $3 d$, it appears that the $\sigma$-potential curve of morpholine is very different from that of $\mathbf{4}$ especially at the level of the left branch which is much steeper downward. This reflects the higher basicity of this cyclic secondary amine ( $\mathrm{pKa}=8.4)$ compared to that of aniline $(\mathrm{pKa}=4.6)$. It is clear that the basicity of morpholine is too high to mimic the poor basicity of acetal 4 coming from the electron pairs of oxygen atoms.

\section{Volatility}

Volatility is an important issue for solvents since it determines their use, recycling and impact on the environment. The directives in force aim at decreasing VOC (Volatile Organic Compound) emissions. Volatility is also a key criterion in applications and often triggers the choice of solvents. It is thus of great interest to evaluate the volatility in comparison to traditional solvents. Volatility depends on various factors, including vapour pressure, vaporisation enthalpy, surface tension and molecular weight. ${ }^{55}$ The volatility of the glycerol acetals/ketals 1 to $\mathbf{4}$ has been evaluated by thermogravimetric analysis (TGA) by measuring the weight loss when submitting each sample to a temperature increase from room temperature to $300{ }^{\circ} \mathrm{C}$ under an inert atmosphere. The thermogravimetric profiles for the four acetals/ketals 1 to 4 are presented in Figure 4 together with the one of dimethyl isosorbide 19 
(DMI), a bio-based solvent that is located close to the VOC limit (b.p. $=236{ }^{\circ} \mathrm{C}$ and $\mathrm{P}_{\text {vap }}=4.1 \mathrm{~Pa}$ at 25 $\left.{ }^{\circ} \mathrm{C}\right){ }^{56}$ For a quantitative comparison of solvents volatility, the temperatures at which $50 \%$ of the compound is vaporised $\left(T_{50 \%}\right)$ have been collected (see ESI). They are compared to various wellknown petrochemical or bio-based oxygenated solvents, in particular glycol ethers (Table 1), studied under the same experimental conditions. Incidentally, it is worth noting that the boiling points of the well-known oxygenated solvents are strongly correlated with $T_{50 \%}$ values (Figure 5 ), and allows an estimation of the b.p. when experimental values are not available (see ESI).

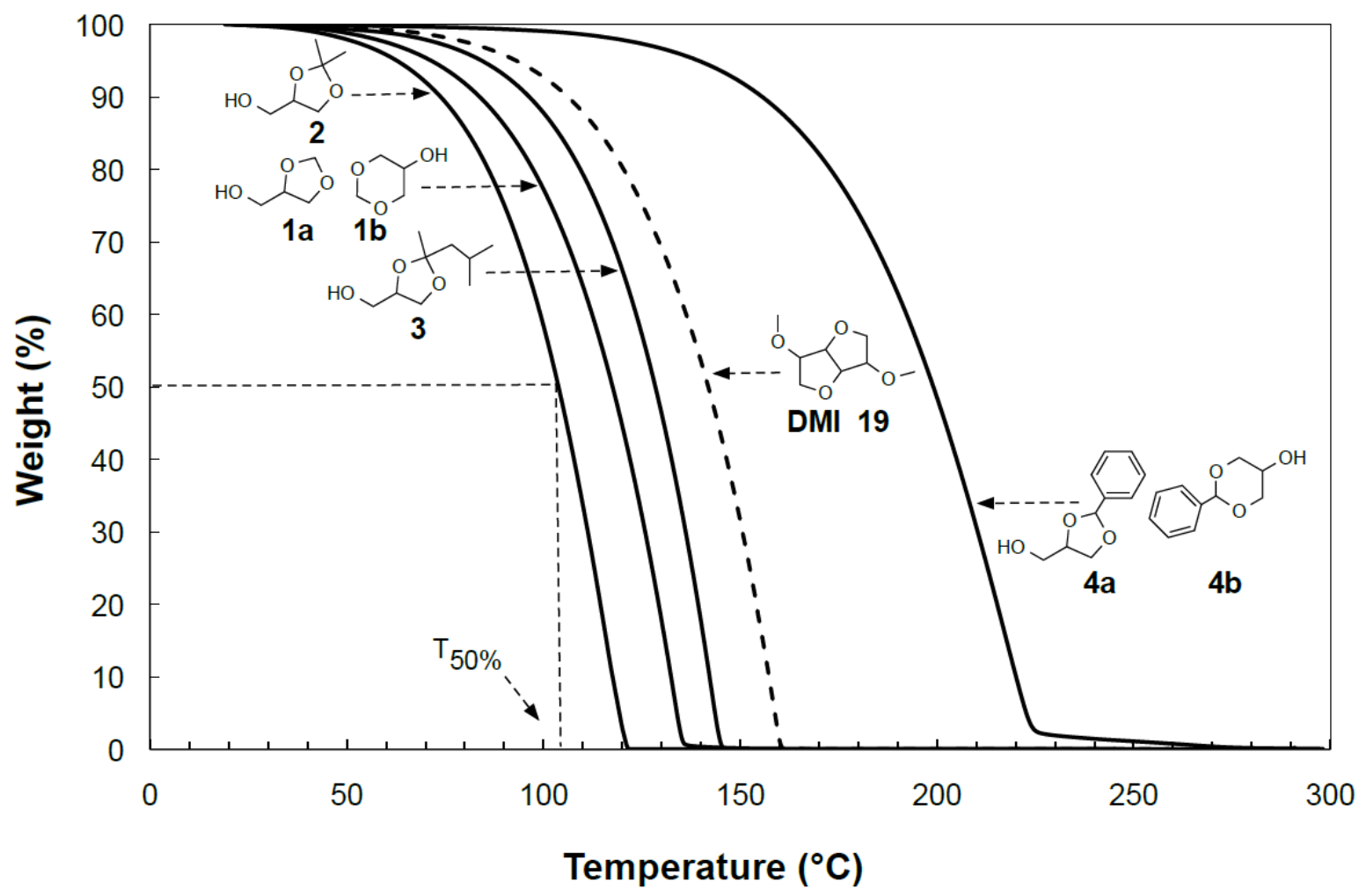

Fig. 4 Thermogravimetric profiles of glycerol acetals/ketals 1-4 (solid lines) and dimethyl isosorbide 19 (dashed line) used as a reference compound to separate VOC from non-VOC solvents. 


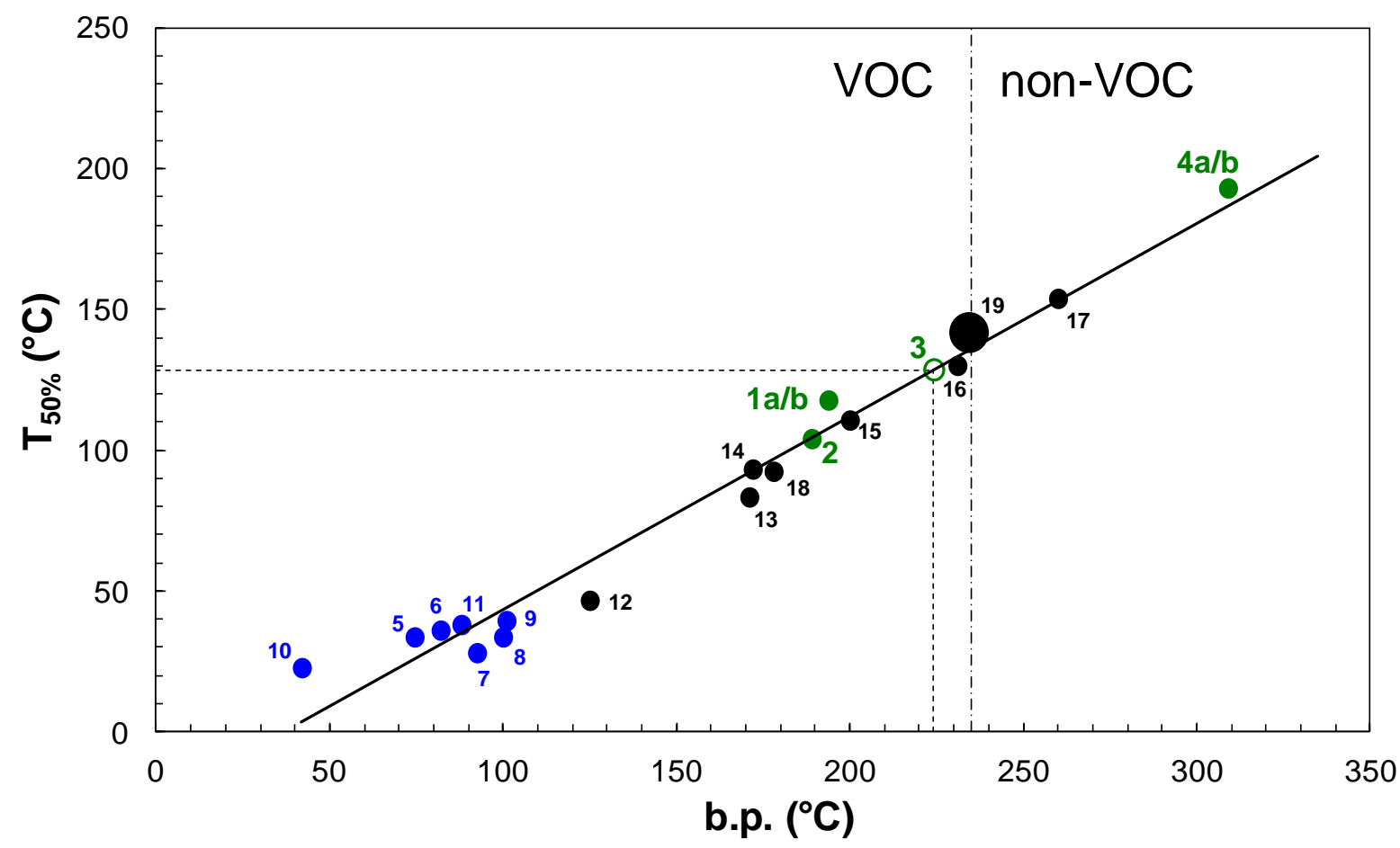

Fig. 5 Correlation between $T_{50 \%}$ and boiling points of glycerol acetals and ketals 1-4 (green dots), traditional acetals 5 - 11 (blue dots) and other oxygenated solvents 12 - 19 (black dots). The boiling point of $\mathbf{3}$ predicted from the experimental $T_{50 \%}$ value is indicated as a green empty dot. Dimethyl isosorbide 19 indicates the limit between VOC and non-VOC compounds and is highlighted as a bigger dot.

Among the four acetals/ketals under study, solketal 2 is unexpectedly more volatile than glycerol formal $\mathbf{1}$, itself more volatile than ketal $\mathbf{3}$. Acetal $\mathbf{4}$ derived from benzaldehyde is much less volatile than the others and is the only non-VOC glycerol derivative. This trend generally follows the molecular weights of the solvents. However the inversion between compounds $\mathbf{1}$ and $\mathbf{2}$ indicates that the structuration in the liquid state is stronger for glycerol formal $\mathbf{1}$ than for solketal $\mathbf{2}$. Also, the low volatility of 4 reflects the strong interactions in the liquid state via $\pi-\pi$ interactions due to the presence of an aromatic ring. It is also noteworthy that, though they have the same number of carbon and oxygen atoms, $\mathbf{2}$ is more volatile than diethylene glycol monoethyl ether $\left(\mathrm{C}_{2} \mathrm{E}_{2}\right)$. In the same way, $\mathbf{3}$ is also more volatile than diethylene glycol hexyl ether $\left(\mathrm{C}_{6} \mathrm{E}_{2}\right)$ although the latter has one additional carbon atom. This indicates that a cyclic acetal function tends to increase the volatility. This result is of particular interest in applications since we have shown in the previous section that glycerol acetals/ketals are relevant candidates for the replacement of glycol ethers.

\section{Hydrolysis in acidic medium}

In order to study the structural effects on the rate of hydrolysis of cyclic acetals/ketals, four petroleumbased cyclic acetals/ketals 5-8 have been studied together with the glycerol derivatives 1-4. The mechanism of acetal or ketal hydrolysis into aldehydes or ketones and alcohols in acidic medium is well known. ${ }^{57}$ It implies two $\mathrm{C}-\mathrm{O}$ bond cleavages, addition of a water molecule and proton transfer (Scheme 1). The rate-determining step is the carbocation $\left(\mathbf{B}^{+}\right)$formation and hydrolysis is favoured when the carbocation is stabilised. 


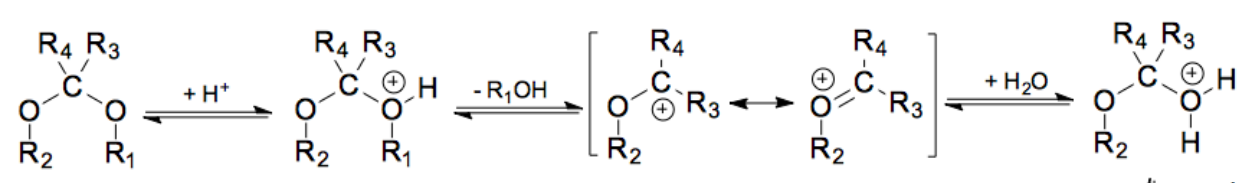

A

$\mathbf{A}^{+}$

$\mathbf{B}^{+}$

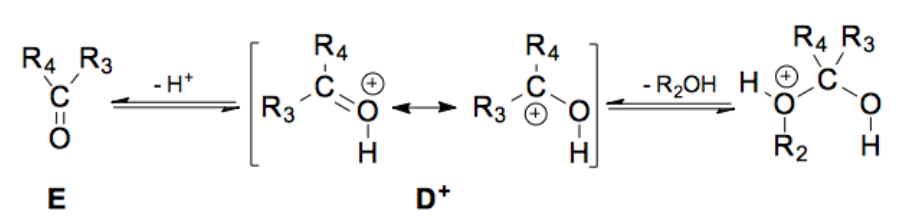

Scheme 1 Mechanism of acetals/ketals hydrolysis in acidic medium.

Hydrolysis of compounds 1 to 4 was monitored by ${ }^{1} \mathrm{H}$ NMR at various $\mathrm{pH}$ ranging from 1.1 to 12.7 at $25^{\circ} \mathrm{C}$. Figure 6 shows the percentage of hydrolysed solketal 2 versus time at five $\mathrm{pH}$ values $(1.7 ; 2.5$; 3.5 and 4.7). Below pH 1.3, hydrolysis is too rapid (less than $10 \mathrm{~min}$ ) whereas above $\mathrm{pH} \mathrm{6}$, no hydrolysis takes place over a two-month period. Similar behaviours were obtained for compounds 5,6 , 7, 8. Glycerol formal $\mathbf{1}$ and 1,3-dioxolane $\mathbf{5}$ are very stable even below pH 1.7. $\mathbf{3}$ and $\mathbf{4}$ are poorly water-soluble and have been considered separately (see below).

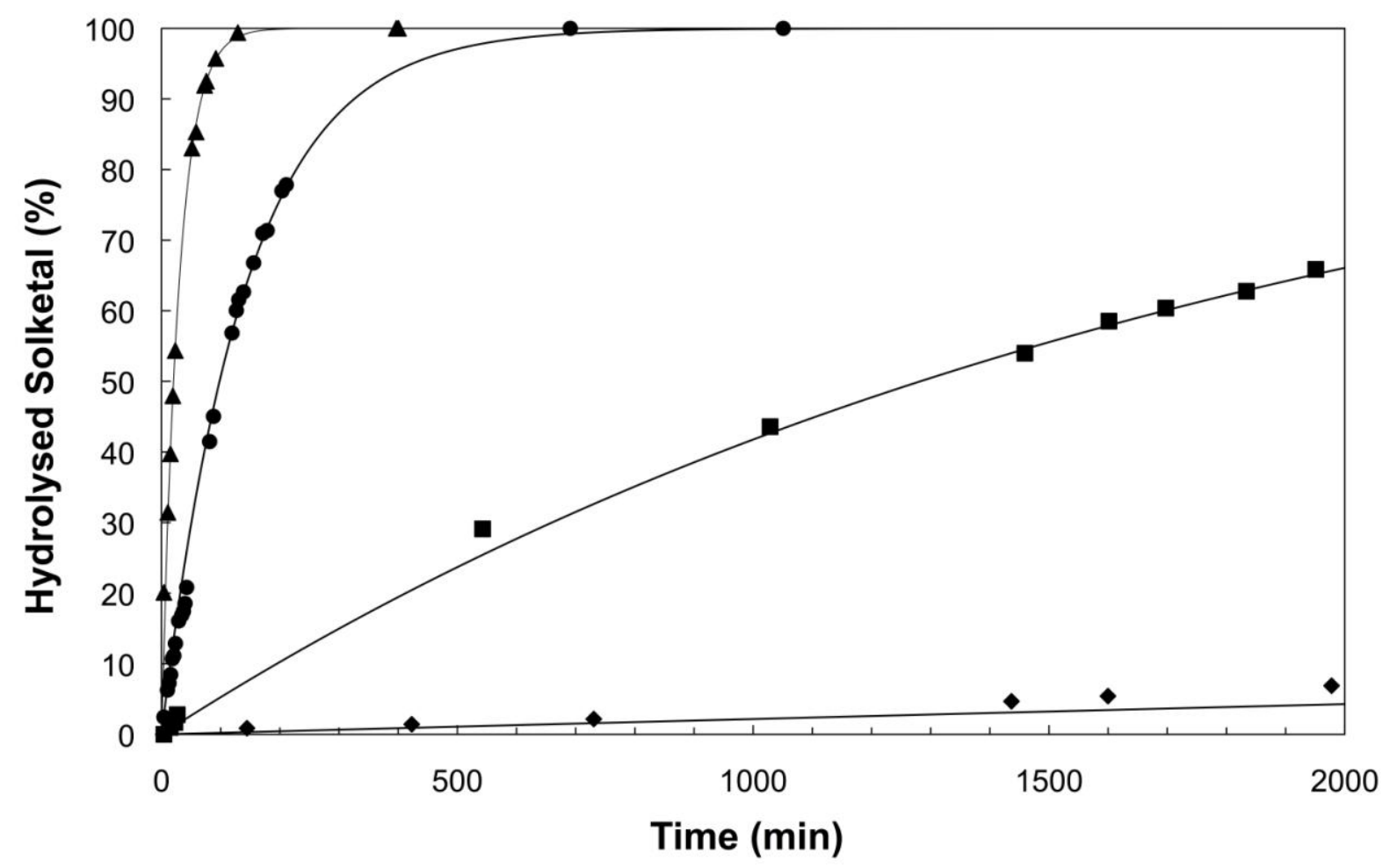

Fig. $6 \mathrm{pH}$ effect on the rate of hydrolysis of solketal 2 determined by ${ }^{1} \mathrm{H}$ NMR at $25 \pm 1{ }^{\circ} \mathrm{C}$. The plotted lines correspond to hydrolysis kinetic modelling $(\mathrm{pH} 1.7 \triangle ; \mathrm{pH} 2.5 \bullet ; \mathrm{pH} 3.5 \bullet ; \mathrm{pH} 4.7 \bullet)$.

Acetal and ketal hydrolysis is modelled by Eq. 1, where $[\mathrm{A}],[\mathrm{E}]$ and $\left[\mathrm{H}_{3} \mathrm{O}^{+}\right]$are the molar concentrations (mol. $\mathrm{L}^{-1}$ ) of acetal / ketal, aldehyde / ketone, and hydronium respectively. $\mathrm{k}$ is the rate constant of hydrolysis and $x$ and $y$ are the partial orders of the reaction with respect to $\mathrm{A}$ and $\mathrm{H}_{3} \mathrm{O}^{+}$ respectively. 


$$
\mathrm{v}=-\frac{\mathrm{d}[\mathrm{A}]}{\mathrm{dt}}=+\frac{\mathrm{d}[\mathrm{E}]}{\mathrm{dt}}=\mathrm{k}[\mathrm{A}]^{\mathrm{x}}\left[\mathrm{H}_{3} \mathrm{O}^{+}\right]^{\mathrm{y}}
$$

$\mathrm{k}_{\mathrm{app}}$ is the apparent rate constant when the $\mathrm{pH}$ is kept constant over the reaction time, which is the case here. It is defined by Eq. 2.

$$
\mathrm{k}_{\mathrm{app}}=\mathrm{k}\left[\mathrm{H}_{3} \mathrm{O}^{+}\right]^{\mathrm{y}}
$$

For all compounds, fitting of the experimental points show that $x$ and $y$ equal 1 and the integration of Eq. 1 gives the evolution of the concentration of acetal / ketal over time (Eq. 3).

$$
[\mathrm{A}]_{\mathrm{t}}=[\mathrm{A}]_{0} \exp \left(-\mathrm{k}\left[\mathrm{H}_{3} \mathrm{O}^{+}\right] \mathrm{t}\right)=[\mathrm{A}]_{0} \exp \left(-\mathrm{k}_{\mathrm{app}} \mathrm{t}\right)
$$

The half-life time $t_{1 / 2}$ is defined as the time at which half of the acetal / ketal is hydrolysed (Eq. 4).

$$
\mathrm{t}_{1 / 2}=\frac{\ln 2}{\mathrm{k}_{\mathrm{app}}}=\frac{\ln 2}{\mathrm{k} \times 10^{-\mathrm{pH}}}
$$

\begin{tabular}{|c|c|c|c|c|c|}
\hline No. & $\begin{array}{c}\text { Solvent } \\
\mathrm{D}_{2} \mathrm{O} / \mathrm{CD}_{3} \mathrm{CN}\end{array}$ & $\mathrm{pH}$ & $\begin{array}{c}k_{\text {app }} \\
\left(\mathrm{min}^{-1}\right) \\
\end{array}$ & $\begin{array}{c}t_{1 / 2} \\
(\min )\end{array}$ & $\begin{array}{c}\mathrm{k} \\
\left(\mathrm{M}^{-1} \cdot \min ^{-1}\right) \\
\end{array}$ \\
\hline $1 \mathrm{a}$ & $100 / 0$ & $1.8-3.5$ & $\approx 0$ & - & $\approx 0$ \\
\hline $1 b$ & $100 / 0$ & $1.8-3.5$ & $\approx 0$ & - & $\approx 0$ \\
\hline 2 & $100 / 0$ & 1.8 & $2.81 \times 10^{-2}$ & 25 & 1.8 \\
\hline 2 & $100 / 0$ & 2.5 & $7.07 \times 10^{-3}$ & 98 & 2.2 \\
\hline 2 & $100 / 0$ & 3.5 & $5.41 \times 10^{-4}$ & 1281 & 1.7 \\
\hline 2 & $83 / 17$ & 1.9 & $2.03 \times 10^{-2}$ & 34 & 1.6 \\
\hline 2 & $67 / 33$ & 2.3 & $7.20 \times 10^{-3}$ & - & 1.4 \\
\hline 3 & $83 / 17$ & 1.9 & $3.98 \times 10^{-2}$ & 17 & 3.2 \\
\hline $4 a$ & $67 / 33$ & 2.3 & $2.30 \times 10^{-2}$ & 30 & 4.6 \\
\hline $4 b$ & $67 / 33$ & 2.3 & $2.90 \times 10^{-3}$ & 239 & 0.6 \\
\hline 5 & $100 / 0$ & $1.8-3.5$ & $\approx 0$ & - & $\approx 0$ \\
\hline 6 & $100 / 0$ & 1.8 & $1.17 \times 10^{-2}$ & 59 & 0.7 \\
\hline 6 & $100 / 0$ & 2.5 & $2.91 \times 10^{-3}$ & 238 & 0.9 \\
\hline 6 & $100 / 0$ & 3.5 & $2.41 \times 10^{-4}$ & 2876 & 0.8 \\
\hline 7 & $100 / 0$ & 1.8 & $1.35 \times 10^{-1}$ & 5 & 8.5 \\
\hline 7 & $100 / 0$ & 2.5 & $3.12 \times 10^{-2}$ & 22 & 9.9 \\
\hline 7 & $100 / 0$ & 3.5 & $2.05 \times 10^{-3}$ & 338 & 6.5 \\
\hline 8 & $100 / 0$ & 1.8 & $1.17 \times 10^{-1}$ & 6 & 7.4 \\
\hline 8 & $100 / 0$ & 2.5 & $2.55 \times 10^{-2}$ & 27 & 8.1 \\
\hline 8 & $100 / 0$ & 3.5 & $2.30 \times 10^{-3}$ & 301 & 7.3 \\
\hline
\end{tabular}

The hydrolysis rate constants $\mathrm{k}$ and $\mathrm{k}_{\mathrm{app}}$ and the half-life times $\mathrm{t}_{1 / 2}$ are reported in Table 3 .

Table3 Half-life times $t_{1 / 2}$ and hydrolysis rate constants $k_{a p p}$ and $k\left(=k_{a p p} /\left[H_{3} \mathrm{O}^{+}\right]\right)$for ketals / acetals 1-8 in $\mathrm{D}_{2} \mathrm{O}$ or in $\mathrm{D}_{2} \mathrm{O} / \mathrm{CD}_{3} \mathrm{CN}$ at various $\mathrm{pH}$.

As the dissociation constants of protonated acetal/ketal $\mathbf{A}^{+}$and hemiacetal/hemiketal $\mathbf{C}^{+}$(see scheme 1) are approximately three times greater in $\mathrm{D}_{2} \mathrm{O}$ than in $\mathrm{H}_{2} \mathrm{O}$, hydrolysis is expected to be three times faster in heavy water than in normal water' the ratio generally varying from 2.3 to $3.4{ }^{57}$ This kinetic isotopic effect has been confirmed for solketal 2 at $\mathrm{pH} 1.8$.

Let us now first consider substituent effect on position $2\left(R_{3} / R_{4}\right.$ groups in Scheme 1). Formaldehydebased acetals $\left(R_{4}=R_{3}=H\right.$, compounds 1 and 5$)$ were found to be stable under our conditions, 
whereas acetone-based ketals (compounds 2, 7 and 8) are hydrolysed much faster. Replacing a methyl group by a hydrogen atom (compound 6) increases significantly the stability in these acidic conditions since the constant is divided by 16 . The more electron-donor $R_{3} / R_{4}$ are, the less stable the compound is. This is consistent with the fact that the rate determining step (r.d.s.) is the carbocation formation in position 2 (step 2 in Scheme 2). ${ }^{57}$

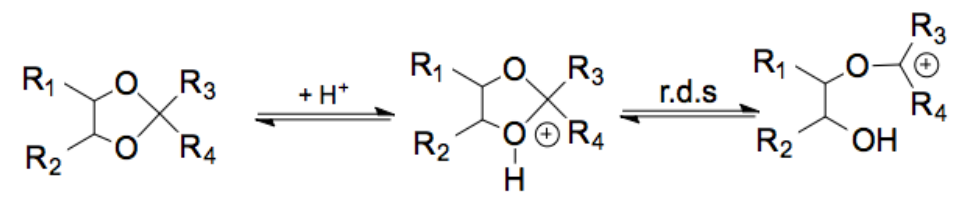

Scheme 2 Cleavage of 1,3-dioxolanes under acidic conditions.

However, even though ketals 2, $\mathbf{7}$ and $\mathbf{8}$ bear the same $\mathrm{R}_{3} / \mathrm{R}_{4}$ groups, they exhibit different hydrolysis stabilities which implies that the substituents in position 4 or $5\left(R_{1} / R_{2}\right)$ also have an impact on hydrolysis, although much weaker than the $R_{3} / R_{4}$ substituents. Ketals 7 and 8 exhibit hydrolysis rate constants of the same order of magnitude. This result is rather surprising because one could expect that methyl group in position 4 (ketal 8) would favour the protonation of the oxygen in position 3 (step 1 , scheme 2) and thus decrease its stability to hydrolysis. Solketal 2 is more stable than ketals 7 and 8, which could be explained by an intramolecular hydrogen bond (see Figure 7) or conformational effects that could make the oxygen atom less electron rich and thus disfavours the protonation step (step 1, scheme 2). Even if one can argue that this intramolecular hydrogen bond established in the pure state is likely to be disrupted or even annihilated in water, in the case of sugars (sucrose for instance), NMR and molecular dynamic studies showed that such bonds are maintained in polar aprotic solvents and are also encountered in water. In this case, the direct intramolecular hydrogen bonds are replaced by indirect ones involving a water molecule. ${ }^{58}$ This kind of intramolecular contribution has already been put forward to rationalize the rate of hydrolysis of comparable acetals bearing a $\mathrm{COOH}$ function at the $\mathrm{C} 4$ instead of the $\mathrm{CH} 2 \mathrm{OH}$ group present in the glycerol acetals. ${ }^{59}$

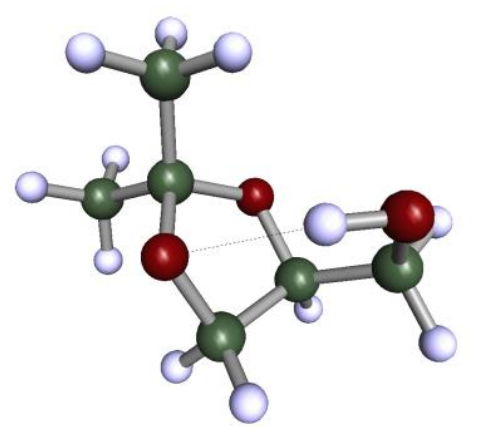

Fig. 7 Intramolecular hydrogen bond than can be established in the case of solketal 2.

As compounds $\mathbf{3}$ and $\mathbf{4}$ are weakly water-soluble, their hydrolysis has been studied in water/acetonitrile mixtures. $\mathrm{D}_{2} \mathrm{O} / \mathrm{CD}_{3} \mathrm{CN}$ (83:17) has been used for compound 3 and hydrolysis was monitored at $\mathrm{pH}$ 1.9. Again, hydrolysis rates have been modelled by Eq. 1 and partial order $\mathrm{x}$ appears to be 1. Rate constants $k$ and $k_{\text {app }}$ and half-life time $t_{1 / 2}$ are given in Table 2. Ketal 3 is hydrolysed three times faster than solketal 2 under the same conditions, in agreement with the conclusions drawn 
above. Finally, hydrolysis of acetal 4 and ketal 2 has been monitored in $\mathrm{D}_{2} \mathrm{O} / \mathrm{CD}_{3} \mathrm{CN}(67: 33)$ at pH 2.3. Acetal $\mathbf{4}$ is composed of the two isomers with five- and six-member rings ( $\mathbf{4 a}$ and $\mathbf{4 b}$ respectively) and the hydrolysis of these two compounds could be monitored separately by ${ }^{1} \mathrm{H}$ NMR. The hydrolysis of the aromatic dioxolane $\mathbf{4 a}$ is 3.2 times faster than that of solketal $\mathbf{2}$ (see Table 2). This behaviour is consistent with the fact that the intermediate carbocation $\mathrm{B}^{+}$(see Scheme 1) is much more stabilised by mesomeric effect of the phenyl group than it is by inductive effect of the methyl group. More unexpectedly, dioxolane $\mathbf{4 b}$ hydrolyses 8 times faster than dioxane $\mathbf{4 a}$. This reactivity difference can be explained by ring strain that is more important in the case of five-member ring than in the case of six-member one. Similar conclusion has been drawn by Watts who compared the hydrolysis of 2methyl-1,3-dioxane and 2-methyl-1,3-dioxolane. ${ }^{60}$

This comparative study allows drawing the following conclusions on the structural effects with regard to the hydrolysis of acetals/ketals in acidic medium. In the case of alkyl derivatives (i) acetals are much more stable than ketal homologues and formaldehyde-based acetals are so stable that no detectable hydrolysis is observed at $\mathrm{pH} 1.8$ within two months, (ii) the more electron-donor the substituent in position 2 is, the less stable the ketal (iii) glycerol-based dioxolanes are more stable than glycol-based ones.

\section{Stability towards autoxidation}

Simple ethers are known to be prone to autoxidation upon prolonged exposure to air giving potentially explosive peroxides. Like linear or cyclic ethers, ${ }^{61}$ acetals and ketals $(R)$ are oxidized with dioxygen according to a radical chain mechanism following three main steps described as initiation, propagation and termination, as depicted by equations 5 to $10 .^{62}$

$$
\begin{array}{ll}
\text { Initiation } & \mathrm{RH} \rightarrow \mathrm{R}^{\bullet} \\
\text { Propagation } & \mathrm{R}^{\bullet}+\mathrm{O}_{2} \rightarrow \mathrm{ROO} \\
& \mathrm{ROO}+\mathrm{RH} \rightarrow \mathrm{ROOH}+\mathrm{R}^{\bullet} \\
\text { Termination } & \mathrm{R}^{\bullet}+\mathrm{R}^{\bullet} \rightarrow \mathrm{R}-\mathrm{R} \\
& \mathrm{R}^{\bullet}+\mathrm{ROO}^{\bullet} \rightarrow \mathrm{ROOR} \\
& \mathrm{ROO}^{\bullet}+\mathrm{ROO}^{\bullet} \rightarrow \text { non radical products }
\end{array}
$$

For ethers, the initiation step involves the abstraction of one of the $\alpha$-hydrogen atoms giving a radical $\mathrm{R} \cdot$ which reacts very rapidly with $\mathrm{O}_{2}$ (eq. 6). The rate determining step corresponds to the abstraction of a hydrogen atom from the substrate by the peroxyl radical ROO ${ }^{\bullet}$ in the propagation step (eq. 7). The hydroperoxides formed as primary oxidation products can further decompose into other radicals or stable secondary oxidation products such as ketones or esters. ${ }^{62}$ In the termination step, two radicals $\mathrm{R}^{\bullet}$ or $\mathrm{ROO}^{\bullet}$ may react providing no-radical products (Eq. 8-10). Various hydrogen atoms of a given acetal/ketal can be abstracted. In particular, the hydrogen atom located between the two ether functions of acetals is more reactive than those of common ethers. ${ }^{61}$ To evaluate the susceptibility of the studied ketals and acetals towards oxidation, we compared them to two relevant reference solvents. The first one, $d$-limonene $\mathbf{2 0}$, is chemically different from solvents $\mathbf{1 - 4}$ but it is a readily 
available bio-solvent widely used in cleaning products and it is known to be air-sensitive giving a mixture of highly allergenic hydroperoxides. ${ }^{63}$ The second one, dimethyl isosorbide 19 (DMI), is a nontoxic cyclic ether derived from sorbitol which is approved for use in cosmetics and pharmaceuticals. The stability of the acetals/ketals 1-4 towards autoxidation was thus assessed and compared to that of the two reference solvents using the PetroOxy apparatus which allows to monitor the consumption of oxygen as a function of time at constant temperature $\left(80^{\circ} \mathrm{C}\right) .{ }^{52}$ The evolution of oxygen pressure, initially fixed at $400 \mathrm{kPa}$, is reported in Figure 8- The loss of oxygen pressure is directly related to the consumed oxygen concentration $\left(\Delta\left[\mathrm{O}_{2}\right]\right)$ according to the following relation: ${ }^{52}$

$$
\Delta\left[\mathrm{O}_{2}\right]_{t}=10^{3} \frac{\left(P_{\max }-P_{t}\right)}{R T} \times \frac{\left(V_{t o t}-V\right)}{V}
$$

where $\Delta\left[O_{2}\right]_{t}$ is the consumed oxygen concentration, $\mathrm{P}_{\max }$ and $\mathrm{P}_{\mathrm{t}}$ are respectively the maximal oxygen pressure and the oxygen pressure at time $t$ measured by the PetroOxy, $\mathrm{V}_{\text {tot }}$ and $\mathrm{V}$ are respectively the volume of the cell and the volume of the solvent under study in $\mathrm{mL}$.

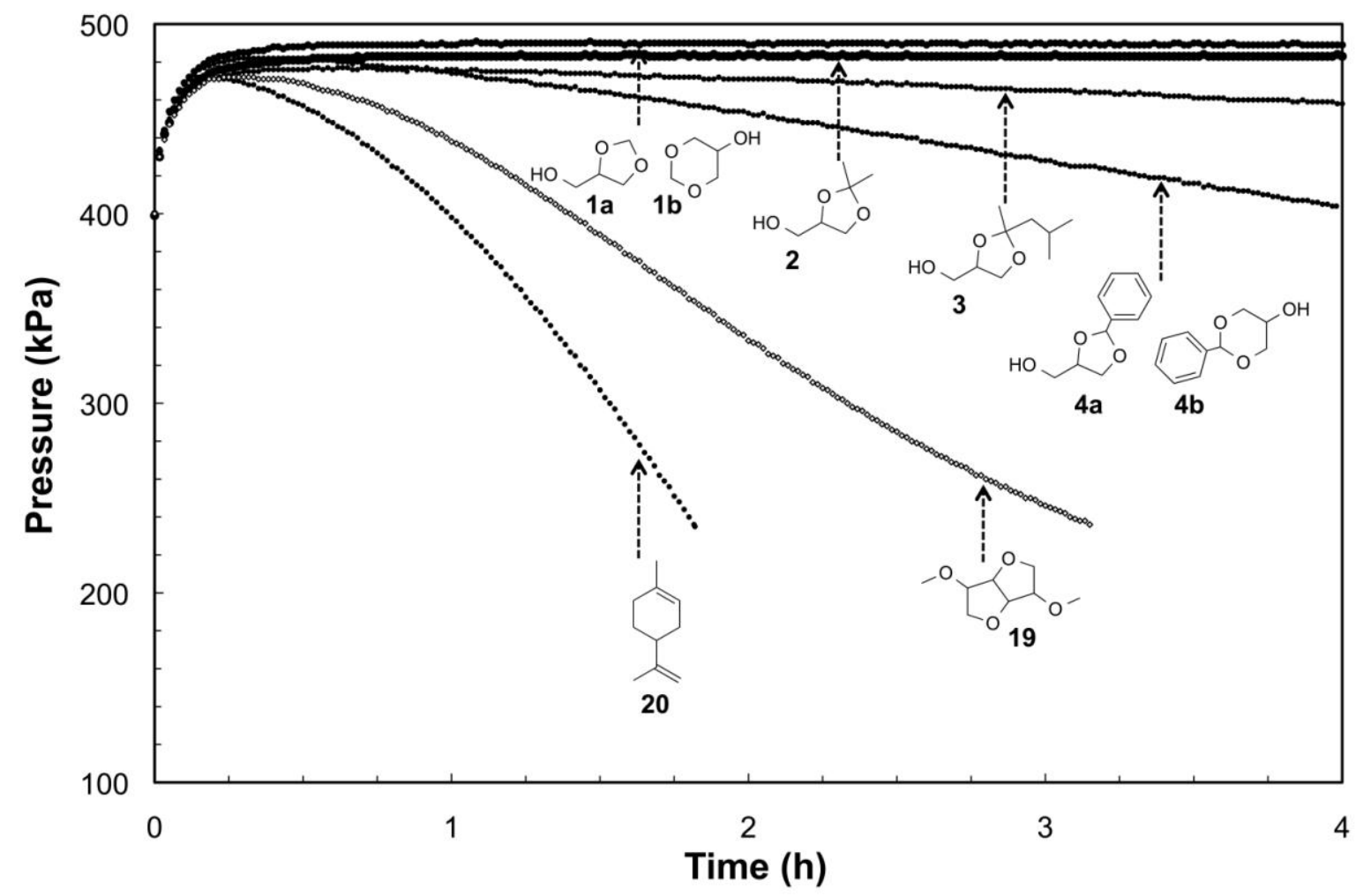

Fig. 8 Monitoring of oxygen consumption with the PetroOxy apparatus during the autoxidation of acetals and ketals 1 to 4 , as well as dimethyl isosorbide 19 and $d$-limonene 20 . Conditions: $2 \mathrm{~mL}$ pure compound, $\mathrm{T}=80^{\circ} \mathrm{C}$, starting pressure $\mathrm{P}\left(\mathrm{O}_{2}\right)=400 \mathrm{kPa}$.

Figure 8 highlights different behaviours of the solvents towards oxidation. First, glycerol formal $\mathbf{1}$ and solketal $\mathbf{2}$ are stable under these conditions since there is no oxygen consumption within 4 hours. In contrast, significant oxygen consumption is observed for ketal $\mathbf{3}$ and aromatic acetal 4. Surprisingly, DMI 19 is more reactive with oxygen than acetals/ketals whereas, as expected, the electron-rich terpene $d$-limonene $\mathbf{2 0}$, is oxidized much faster than any other compound under study. 
The oxidation rate of ketals and acetals is mainly governed by the kinetically determining step (eq. 7). The homolytic Bond Dissociation Energy (BDE) of the weakest $\mathrm{C}-\mathrm{H}$ bonds of the substrate is one of the key thermodynamic parameter to rationalize the oxidability of a compound. ${ }^{64,65}$ Generally speaking, the lower the BDE, the higher the propagation rate is. ${ }^{52}$ Calculations of the BDEs of the C-H bonds using the DFT method B3LYP 6-311G $(2 d, 2 p)$ have been performed for the different solvents. Figure 9 shows the most labile hydrogen(s) of each solvent ranked on a scale of increasing BDEs. $A$ limited number of general rules are known to govern the ease of abstracting the hydrogen atom from a C-H bond: ${ }^{61,66}$

(i) The $\mathrm{C}-\mathrm{H}$ bond energy decreases with increasing substitution primary $>$ secondary $>$ tertiary since the resulting radicals are stabilised by the electro-donating inductive effect of the alkyl groups.

(ii) A $\alpha$-phenyl group, a $\alpha$-oxygen and a $\alpha$-double bond considerably decrease the BDE.

(iii) The abstraction of a $\alpha$-hydrogen from 5 -membered cyclic ethers (tetrahydrofurans) is easier than from the less strained 6-membered cyclic ethers (tetrahydropyrans) which in turn is easier than from the non-strained linear ether.

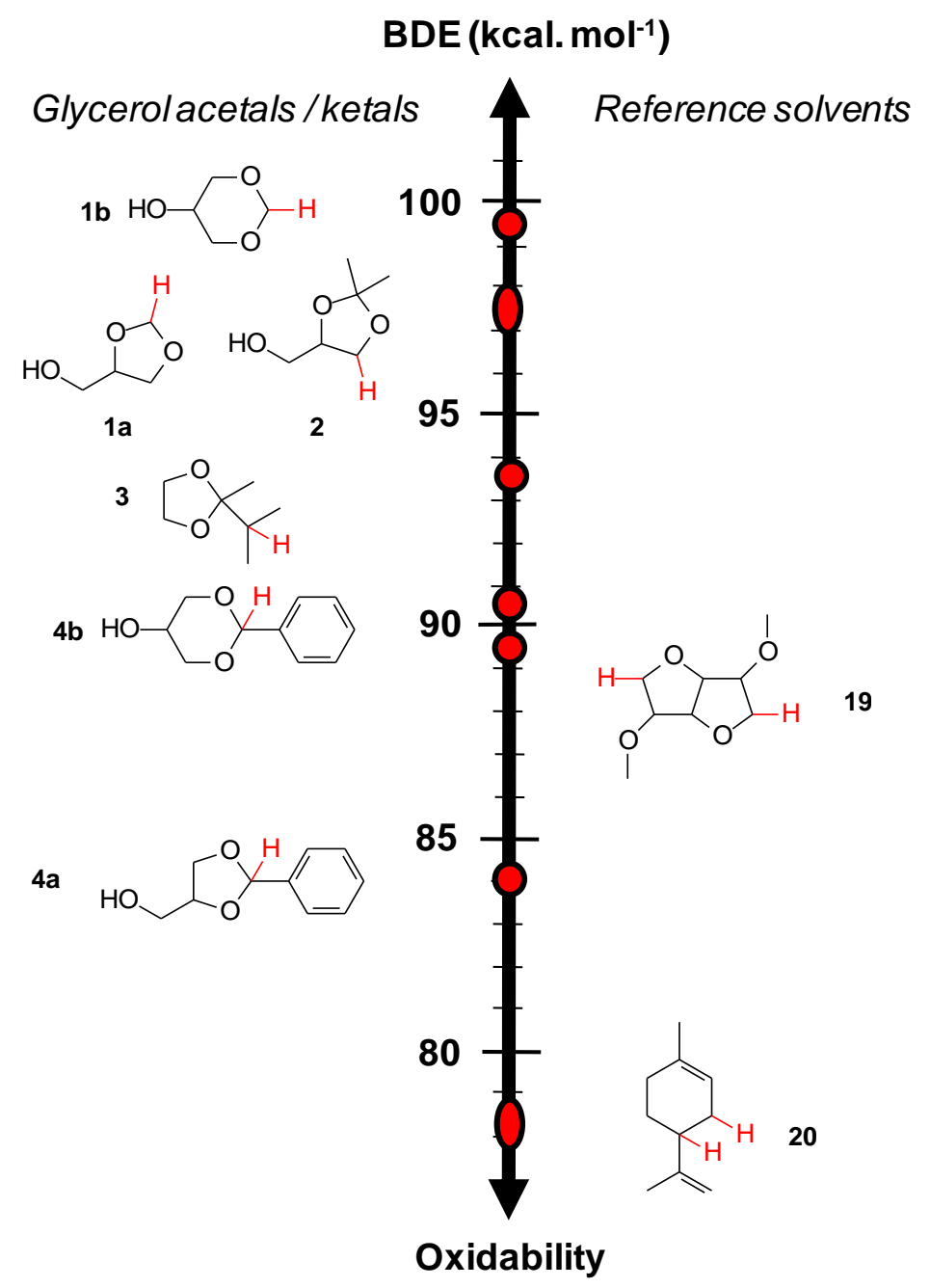

Fig. 9 Scale of oxidability of solvents 1-4 showing the weakest BDEs of each compound (in red) in comparison to reference solvents: limonene 20 and dimethyl isosorbide 19. 
The order of the lowest BDEs of each solvent is in agreement with the above rules: 20 (allylic positions of an electron-rich cyclohexene) $<4 \mathbf{a}$ (dioxolane with one $\alpha$-phenyl and two $\alpha$-oxygens) $<4 \mathbf{b}$ (dioxane with one $\alpha$-phenyl and two $\alpha$-oxygens) $<19$ (two strained 5-membered rings with two secondary $\mathrm{C}-\mathrm{H}$ and four tertiary $\mathrm{C}-\mathrm{H}$ in $\alpha$ position of an ether group) $<3$ (one tertiary $\mathrm{C}-\mathrm{H}$ ) $<\mathbf{1 a}$ (dioxolane with two $\alpha$ oxygens) $\approx 2$ (electron-rich dioxolane with one $\alpha$-oxygen) $<\mathbf{1 b}$ (dioxane with two $\alpha$-oxygens). Moreover, as expected, this scale based on BDE values is also in fair agreement with their reactivity towards oxygen confirming that limonene $\mathbf{2 0}$ is by far, the most oxidizable solvent. However, dimethyl isosorbide 19 appears to be more reactive than $\mathbf{4}$ despite their respective BDE values. Indeed, DMI has six times as many abstractable hydrogen atoms as $\mathbf{4}$ per molecule. Furthermore once a first hydrogen is abstracted, it forms a peroxyl radical ROO - which reacts very quickly with a second hydrogen in the same molecule of DMI while the propagation reaction (Eq. 7) of the peroxyl radical derived from $\mathbf{4}$ will be necessarily intermolecular and therefore slower than an intramolecular reaction. 


\section{EXPERIMENTAL}

\section{Material}

Glycerol formal 1 was obtained from Glacon Chemie (99\%-0.013\% wt./wt. BHT), 2-isopropylidene glycerol (solketal) 2 was from Sigma-Aldrich (98\%) and 1,2-methylisobutylidene glycerol 3 was a gift from Solvay (98\%). Glycerol formal 1 is a mixture of dioxolane (1a): dioxane (1) isomers 34:66 (molar ratio) as determined by ${ }^{1} \mathrm{H}$ NMR $\left(\mathrm{CDCl}_{3}\right)$. The sample of benzaldehyde glycerol acetal (BGA) 4 used for hydrolysis and autoxidation studies is a mixture of dioxolane (4a):dioxane (4b) isomers 66:34 (molar ratio) as determined by ${ }^{1} \mathrm{H}$ NMR $\left(\mathrm{CDCl}_{3}\right)$.

For volatility, hydrolysis or autoxidation comparative studies, 1,3-dioxolane 5, 2-methyl-1,3-dioxolane 6, 2,2-dimethyl-1,3-dioxolane 7, 2,2,4-trimethyl-1,3-dioxolane 8, 1,4-dioxane 9, methylal 10, ethylal 11, $n$-butyl acetate 12, ethylene glycol $n$-butyl ether $\left(\mathrm{C}_{4} \mathrm{E}_{1}\right)$ 13, propylene glycol $n$-butyl ether $\left(\mathrm{C}_{4} \mathrm{P}_{1}\right) \mathbf{1 4}$, diethylene glycol ethyl ether $\left(C_{2} E_{2}\right)$ 15, diethylene glycol butyl ether $\left(C_{4} E_{2}\right)$ 16, diethylene glycol hexyl ether $\left(\mathrm{C}_{6} \mathrm{E}_{2}\right) \mathbf{1 7}$, tetrahydrofurfuryl alcohol 18 , dimethyl isosorbide 19 , decanal and limonene were obtained from Sigma-Aldrich, Alfa Aesar and TCI Europe (> 98\%). Commercial samples were distilled under reduced pressure to remove possible antioxidants and were kept under argon afterwards.

For hydrolysis studies, $\mathrm{D}_{2} \mathrm{O}$ (Eurisotop, > 99.9\%), $\mathrm{CD}_{3} \mathrm{CN}$ (Eurisotop, > 99.9\%), acetonitrile (HPLC grade, Fluka), dimethylformamide (SDS, 99.9\%), phosphoric acid (Aldrich Chemie, 85\%) and sodium hydroxide (Sigma-Aldrich, 97\%) were used.

\section{Preparation of benzaldehyde glycerol acetal $4 a+4 b$}

Benzaldehyde glycerol acetal $\mathbf{4} \mathbf{a}+\mathbf{4} \mathbf{b}$ was prepared by acetalisation of glycerol with benzaldehyde using an acidic Amberlyst 15 resin. Details can be found in ESI. The ratio between dioxolane and dioxane isomers varies a little with temperature and reaction time. The final composition is always slightly in favour of the dioxolane isomer.

\section{Hansen parameters}

Hansen parameters of the four glycerol acetals/ketals and other relevant solvents have been calculated using the Yamamoto Molecular Breaking (Y-MB) method implemented in the HSPiP software (HSPiP, version 4.0.05). The parameters of classical solvents positioned for comparison in Figure 2 are the ones provided by Hansen. ${ }^{50}$ The distance $D_{\text {Hansen }}$ in the Hansen's space is calculated according to the recommended method (Eq. 11). ${ }^{50}$

$D_{\text {Hansen }}=\sqrt{4\left(\delta_{d(\text { solvent })}-\delta_{d(\text { compound })}\right)^{2}+\left(\delta_{p(\text { solvent })}-\delta_{p(\text { compound })}\right)^{2}+\left(\delta_{h(\text { solvent })}-\delta_{h(\text { compound })}\right)^{2}}$

\section{COSMO-RS calculations}

ArgusLab (ArgusLab 4.0.1, Planaria Software LLC, Seattle, USA) was used to sketch molecules. Conformational analysis was performed by the COSMOconf script. Molecular geometries were optimized thanks to full DFT/COSMO calculations, carried out using the quantum chemical program TURBOMOLE (TURBOMOLE GmbH, Karlsruhe, Germany) with Ahlrichs' triple zeta valence polarization basis set and the Becke-Perdew density functional. COSMOtherm (C31_1301 version, COSMOlogic, Leverkusen, Germany) was used for statistical thermodynamics calculations, including generation of $\sigma$-potentials. These $\sigma$-potentials were then used as described before ${ }^{7,51}$ to position the 
solvents in the COSMO-RS space. The closest neighbours were identified by calculating a distance

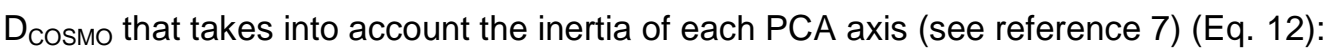

$D_{\text {CoSMo }}=\sqrt{0.395\left(F_{1(\text { solvent })}-F_{1(\text { compound })}\right)^{2}+0.344\left(F_{2(\text { solvent })}-F_{2(\text { compound })}\right)^{2}+0.123\left(F_{3(\text { solvent })}-F_{3(\text { compound })}\right)^{2}+0.102\left(F_{4(\text { solvent })}-F_{4(\text { compound })}\right)}$

TGA measurements

Volatility was evaluated by thermogravimetric analysis TGA by recording the weight loss when imposing a temperature ramp from room temperature to $300{ }^{\circ} \mathrm{C}$ at a rate of $10{ }^{\circ} \mathrm{C} \cdot \mathrm{min}^{-1}$. Thermogravimetric analyses were performed on a TGA Q50 from TA Instruments. The atmosphere of the measuring chamber was pure nitrogen to avoid possible oxidation of the solvents at high temperatures. About $20 \mathrm{mg}$ of compound were deposited on a platinum sample holder. The temperature at which half of the sample was vaporised $\left(T_{50 \%}\right)$ was recorded. The reproducibility was checked thanks to the reference sample (dimethyl isosorbide 19) and was within $\pm 3^{\circ} \mathrm{C}$.

\section{Hydrolysis}

In a glass NMR tube, 0.1 to $0.3 \mathrm{~mol} . \mathrm{L}^{-1}$ of acetal/ketal $(10 \mu \mathrm{L})$ was added to $500 \mu \mathrm{L}$ of a $\mathrm{D}_{2} \mathrm{O}$ solution, containing $10 \mu \mathrm{L}$ of acetonitrile or $10 \mu \mathrm{L}$ of DMF as internal standards. For ketal $\mathbf{3}$ and acetal $\mathbf{4}$, $\mathrm{CD}_{3} \mathrm{CN}$ was also added to ensure complete miscibility. The $\mathrm{pH}$ of the solutions was adjusted with phosphoric acid or sodium hydroxide. Acetal/ketal hydrolysis was monitored by recording the ${ }^{1} \mathrm{H}$ NMR spectra on a Bruker AC spectrometer at $300.13 \mathrm{MHz}$ for ${ }^{1} \mathrm{H}$ at $25 \pm 1^{\circ} \mathrm{C}$ as a function of time. The $\mathrm{pH}$ was measured using a $\mathrm{pH}$ meter ( $\mathrm{pH}$ 330i/SET, WTW) equipped with a combined $\mathrm{pH}$ electrode Sentix 81 (Glass electrode, WTW) including a temperature probe. Electrode calibration was carried out with $\mathrm{pH} \mathrm{4,} 7$ and 10 buffers beforehand.

\section{Autoxidation}

$2 \mathrm{~mL}$ of acetal/ketal free of antioxidant were oxidized at $80^{\circ} \mathrm{C}$ under an atmosphere of pure dioxygen (400 kPa) using the PetroOxy apparatus (Petrotest, Anton Parr). The compound was introduced at room temperature in an inox cell $(20 \times 40 \times 26 \mathrm{~mm})$ that was then purged and filled with pure dioxygen at the desired pressure. The cell was then heated up to $80^{\circ} \mathrm{C}$ and the oxygen pressure was monitored every minute. Further details about the PetroOxy apparatus are given in reference 52.

\section{Calculation of Bond Dissociation Energies (BDE)}

Calculation of Bond Dissociation Energies (BDE) was performed by using Gaussian 03 packages. The geometries of all the parent molecules were firstly optimised by using the PM3 method and then the DFT one by using the B3LYP/6-311G $(d, p)$ basis set. Orbitals from this method were used as inputs to the final RB3LYP/6-311G++ $(2 d, 2 p)$ calculation. The conformer with the lowest electronic energy was used in this work. For radicals, the optimisation also used the PM3 step plus the final UB3LYP/6-311G $(d, p)$ method. The orbitals were then used as inputs to the final UB3LYP/6-311G++ $(2 d, 2 p)$ calculation. Table 3 shows the chemical structure of the oxygenated solvents studied in this work. Relevant properties (boiling points, thermogravimetric data, Hansen solubility parameters and COSMO-RS coordinates) in the PCA space can be found in ESI. 


\section{CONCLUSION}

In this work, four recently launched acetals/ketals of glycerol 1-4 have been investigated as bio-based solvents, with special emphasis on their solubilising properties and on their stabilities towards hydrolysis and oxidation. The evaluation of the solvent properties through Hansen and COSMO-RS approaches indicate that this family of solvents could represent interesting alternatives to some harmful solvents including glycol ethers and aniline. One possible limitation of glycerol acetals/ketals is their sensitivity to hydrolysis in acidic conditions. In-depth kinetic studies on a series of acetals/ketals showed that structural modifications have a great impact on the hydrolysis rate. Acetals are less sensitive than ketals and dioxolane acetals are hydrolysed faster than their dioxane counterparts. Dioxolane derivatives are also more sensitive to autoxidation than their dioxane counterpart in agreement with the Bond Dissociation Energies calculations. Controlling the dioxolane/dioxane ratio during synthesis is thus of utmost importance. It is worth noting that glycerol formal $\mathbf{1}$ is the most stable towards both hydrolysis and autoxidation. Table 4 summarizes the main results of the present paper.

Table 4 Comparison of the relative stabilities of the glycerol acetals and ketals towards hydrolysis and autoxidation. The third column indicates the time required to oxidize $10 \%$ of the solvent at $80{ }^{\circ} \mathrm{C}\left(\mathrm{t}_{10 \%}\right)$. The last column contains the hazardous solvent having the closest solvency properties to the ones of the glycerol acetals/ketals.

\begin{tabular}{cccc}
\hline $\begin{array}{c}\text { Ketal/Acetal } \\
\text { solvent }\end{array}$ & $\begin{array}{c}\text { Hydrolysis } \\
\mathrm{k}\left(\mathrm{M}^{-1} \cdot \mathrm{min}^{-1}\right)\end{array}$ & $\begin{array}{c}\text { Autoxidation } \\
\mathrm{t}_{10 \%} \text { at } 80^{\circ} \mathrm{C}(\mathrm{h})\end{array}$ & $\begin{array}{c}\text { Closest } \\
\text { harmful solvents }\end{array}$ \\
\hline $\mathbf{1 a} / \mathbf{1 b}$ & stable & stable & aniline / glycol ethers \\
$\mathbf{2}$ & 1.9 & stable & glycol ethers \\
$\mathbf{3}$ & 3.2 & 6 & nitroethane \\
$\mathbf{4 a / 4 b}$ & $4.6 / 0.6$ & 2.5 & aniline / nitroethane \\
\hline
\end{tabular}

This work shows that acetals/ketals of polyols may represent an interesting class of solvents to develop from the biomass feedstock. Glycerol formal and solketal are already presented as lowtoxicity and environmentally-friendly bio-based solvents. The good choice of aldehyde/ketone used for the synthesis should allow controlling the stability towards hydrolysis and oxidation and tune the solvent properties of the final product.

\section{SUPPLEMENTARY MATERIAL}

Electronic supplementary information (ESI) available: Physicochemical properties of acetals / ketals and various oxygenated solvents, details and discussion about the synthesis of benzaldehyde glycerol acetal 4, Hansen solubility parameters and COSMO-RS coordinates of 88 tradition solvents of Hansen's work ${ }^{50}$, as well as the ranking of the 88 solvents as regards to their proximity to acetals $\mathbf{1}$ to 4 according to Hansen's approach and COSMO-RS. 


\section{ACKNOWLEDGEMENTS}

This work was performed within the framework of the InBioSynSolv project supported by the French ANR CP2D program (no. ANR-CP2D-2009-08). Solvay is acknowledged for providing samples of 2isopropylidene glycerol and 1,2-methylisobutylidene glycerol. We thank Dr. Frédéric Cazaux (UMET, Lille) for the TGA measurements, Dr. Zéphirin Moulounguil ${ }^{b, c}$ and Dr. Manon Bergez-Lacoste ${ }^{b, c}$ for their contributions to the InBioSynSolv project, and Romain Guitard $^{\text {a }}$ for his contribution to the calculations of BDE. 


\section{REFERENCES}

1. F. M. Kerton, Alternative Solvents for Green Chemistry, RSC, Cambridge, UK, 2009.

2. P. De Caro and S. Thiébaud-Roux, Biosolvants, Ed. Techniques Ingénieur, IN 102, 2008.

3. P. G. Jessop, Green Chem., 2011, 13, 1391-1398.

4. B. Zhou, J. Yang, M. Li and Y. Gu, Green Chem., 2011, 13, 2204-2211.

5. J. Yang, J. N. Tan and Y. Gu, Green Chem., 2012, 14, 3304-3317.

6. M. Sutter, L. Pehlivan, R. Lafon, W. Dayoub, Y. Raoul, E. Métay and M. Lemaire, Green Chem., 2013, 15, 3020-3026.

7. L. Moity, M. Durand, A. Benazzouz, C. Pierlot, V. Molinier and J. M. Aubry, Green Chem., 2012, 14, 1132-1145.

8. L. Moity, V. Molinier, A. Benazzouz, R. Barone, P. Marion and J. M. Aubry, Green Chem., 2014, 16, 146-160.

9. T. Werpy and G. Petersen, Top Value Added Chemicals from Biomass: Volume I -- Results of Screening for Potential Candidates from Sugars and Synthesis Gas, Report DOE/GO-1020041992, 2004.

10. A. Corma, S. Iborra and A. Velty, Chem. Rev., 2007, 107, 2411-2502.

11. J. J. Bozell and G. R. Petersen, Green Chem., 2010, 12, 539-554.

12. R. A. Sheldon, Green Chem., 2014, 16, 950-963.

13. M. Pagliaro, R. Ciriminna, H. Kimura, M. Rossi and C. Della Pina, Angew. Chem. Int. Ed., 2007, 46, 4434-4440.

14. D. T. Johnson and K. A. Taconi, Environ. Prog., 2007, 26, 338-348.

15. A. Behr, J. Eilting, K. Irawadi, J. Leschinski and F. Lindner, Green Chem., 2008, 10, 13-30.

16. C. H. Zhou, J. N. Beltramini, Y. X. Fan and G. Q. Lu, Chem. Soc. Rev., 2008, 37, 527-549.

17. B. Katryniok, S. Paul, V. Belliere-Baca, P. Rey and F. Dumeignil, Green Chem., 2010, 12, 20792098.

18. A. Martin and M. Richter, Eur. J. Lipid Sci. Technol., 2011, 113, 100-117.

19. F. Jérôme and J. Barrault, Eur. J. Lipid Sci. Technol., 2011, 113, 118-134.

20. A. E. Diaz-Alvarez, J. Francos, B. Lastra-Barreira, P. Crochet and V. Cadierno, Chem. Comm., 2011, 47, 6208-6227.

21. Y. Gu and F. Jérôme, Green Chem., 2010, 12, 1127-1138.

22. J. I. Garcia, H. Garcia-Marin, J. A. Mayoral and P. Perez, Green Chem., 2010, 12, 426-434.

23. J. I. Garcia, H. Garcia-Marin and E. Pires, Green Chem., 2014, 16, 1007-1033.

24. Y. Gu and F. Jérôme, Chem. Soc. Rev., 2013, 42, 9550-9570.

25. H. Garcia, O. I. Garcia and J. M. Fraile, Chimica oggi, 2008, 26, 10-12.

26. J. L. Couturier, J. P. Lallier and J. L. Dubois, Arkema France, Use of Glycerol Acetals as Coalescing Agents for Lacquers, Paints or Varnishes and Composition Thereof, WO 2011/042652 A1, 2011.

27. J. Bigorra Llosas, S. Sato, C. Bueno Ramiro, E. Graupera, Cognis, Use of Glycerol Acetals, EP 2 0050784 A1, 2007. 
28. D. H. Bonifacio, J. D. Vicentim, P. R. Garbelotto, Rhodia, Aqueous Formulations Including Dioxolanes as Coupling Agents, WO2011/048481 A1, 2011.

29. C. Estévez Company, N. Bayarri Ferrer, J. Castells Boliart, Institut Univ. De Ciència i Tecnologia, Proceso Para La Preparacion De Loperamida, ES2387793T3, 2008.

30. A. Pirotte, Agriphar, Improved Method for Producing Emulsifiable Pesticide Solutions, WO201311108, 2013.

31. G. Lambiotte, Composition Insecticide, CH 690259 A5, 1995.

32. R. P. V. Faria, C. S. M. Pereira, V. M. T. M. Silva, J. M. Loureiro and A. E. Rodrigues, Chem. Eng. J., 2013, 233, 159-167.

33. P. Sudarsanam, B. Mallesham, A.N. Prasad, P.S. Reddy and M. Reddy, Fuel Process. Technol., 2013, 106, 539-545.

34. N. Rahmat, A.Z. Abdullah and A.R. Mohamed, Renew. Sust. Energ. Rev., 2010, 14, 987-1000.

35. G. S. Nair, E. Adrijanto, A. Alsalme, I. V. Kozhevnikov, D. J. Cooke, D.R. Brown and N. R. Shiju, Catal. Sci. Technol., 2012, 2, 1173-1179.

36. P. H. R. Silva, V. L. C. Gonçalves and C. J. A. Mota, Bioresour. Technol., 2010, 101, 6229-6255.

37. C. Crotti, E. Farnetti and N. Guidolin, Green Chem., 2010, 12, 2225-2231.

38. V. R. Ruiz, A. Velty, L. L. Santos, A. Leyva-Pérez, M. J. Sabater, S. Iborra and A. Corma, J. Catal., 2010, 271, 351-357.

39. B. L. Wegenhart and M. M. Abu-Omar, Inorg. Chem., 2010, 49, 4741-4743.

40. P. S. Reddy, P. Sudarsanam, G. Raju and B. M. Reddy, J. Ind. Eng. Chem., 2012, 18, 648-654.

41. H. Serafim, I. M. Fonseca, A. M. Ramos, J. Vital and J. E. Castanheiro, Chem. Eng. J., 2011, 178, 291-296.

42. C. X. A. Desilva, V. L. C. Gonçalves and C. J. A. Mota, Green Chem., 2009, 11, 38-41.

43. J. Deutsch, A. Martin and H. Lieske, J. Catal., 2007, 245, 428-435.

44. M.B. Güemez, J. Requies, I. Agirre, P.L. Arias, V. L. Barrio and J.F. Cambra, Chem. Eng. J., 2013, 228, 300-307.

45. S.B. Umbarkar, T.V. Kotbagi, A.V. Biradar, R. Pasricha, J. Chanale, M.K. Dongare, A-S. Mamede, C. Lancelot and E. Payen, J. Mol. Catal. A-Chem., 2009, 310, 150-158.

46. B. Thomas, V.G. Ramu, S. Gopinath, J. George, M. Kurian, G. Laurent, G.L. Drisko and S. Sugunan, App. Clay Sci., 2011, 53, 227-235.

47. G. Vincente, J.A. Melero, G. Morales, M. Paniagua and E. Martin, Green Chem., 2010, 12, 899907.

48. F. Adam, M.S. Batagarawa, K.M. Hello and S.S. Al-juaid, Chem. Pap., 2012, 66, 1048-1058.

49. C. Gonzalez-Arellano, R.A.D. Arancon and R. Luque, Green Chem., 2014, 16, 4985-4993.

50. C. M. Hansen, Hansen Solubility Parameters: A User's Handbook, Second Edition, CRC Press, Boca Raton, 2007.

51. M. Durand, V. Molinier, W. Kunz and J. M. Aubry, Chem. Eur. J., 2011, 17, 5155-5164.

52. C. Marteau, F. Ruyffelaere, J. M. Aubry, C. Penverne, D. Favier and V. Nardello-Rataj, Tetrahedron, 2013, 69, 2268-2275. 
53. A. Benazzouz, L. Moity, C. Pierlot, M. Sergent, V. Molinier and J. M. Aubry, Ind. Eng. Chem. Res., 2013, 52, 16585-16597.

54. A. Benazzouz, L. Moity, C. Pierlot, V. Molinier and J. M. Aubry, Colloids Surf. A, 2014, 458, 101109.

55. P. Rahimi and C. A. Ward, Int. J. Thermodyn., 2005, 8, 1-14.

56. M. Durand, Propriétés physico-chimiques, fonctionnelles et applicatives des éthers courts d'isosorbide, PhD, Université de Lille 1, 2010.

57. E. H. Cordes and H. G. Bull, Chem. Rev., 1974, 74, 581-603.

58. S. Immel and F.W. Lichtenthaler, Liebigs Ann. 1995, 1925-1935.

59. T. C. Bruice and D. Piszkiewicz, J. Am. Chem. Soc., 1967, 89, 3568-3576.

60. P. Watts, J. Chem. Soc. B, 1968, 543-545.

61. E. T. Denisov and I. B. Afanas'ev, Oxidation and Antioxidants in Organic Chemistry and Biology, Taylor \& Francis, 2005.

62. D. L. Rakhmankulov, S. S. Zlotsky, E. M. Kuramshin and L. G. Kulak, Intern. J. Polymer. Mater., 1990, 13, 113-122.

63. A-T. Karlberg, L.P. Shao, U. Nilsson, E. Gäfvert, J.L. Nilsson, Arch. Dermatol. Res. 1994, 286, 97-103

64. D. A. Pratt, J. H. Mills and N. A. Porter, J. Am. Chem. Soc., 2003, 125, 5801-5810.

65. S. Korcek, J. H. B. Chenier, J. A. Howard and K. U. Ingold, Can. J. Chem., 1972, 50, 2285-2297.

66. J.A. Howard, K.U. Ingold Can. J. Chem. 1969, 47, 3809-3815. 